\title{
La metrología histórica como herramienta para la Arqueología de la Arquitectura. La experiencia en los Reales Alcázares de Sevilla
}

\author{
Metrics as a Building Archaeology tool. \\ The experience at the Royal Alcazar of Seville
}

\author{
Alejandro Jiménez Hernández \\ Colaborador del Proyecto de Excelencia Análisis Estratigráfico y Cronotipológico de los Recintos Fortificados del Alcázar de Sevilla. \\ Procedimientos, Sistemas y Aplicaciones desde su Vertiente Constructiva. (P12-TEP-1843) \\ ajharqu@gmail.com
}

\begin{abstract}
RESUMEN
La caracterización métrica de materiales de construcción, estructuras y edificios asociada a los distintos sistemas de pesas y medidas históricos es una potente herramienta para la adscripción cultural y cronológica, como muestra su aplicación práctica en el Real Alcázar de Sevilla. El análisis dimensional de diversos ejemplos de arquitectura islámica nos muestra la difusión del sistema de medidas islámico en todos los territorios bajo su dominio.
\end{abstract}

Palabras clave: Sistema de pesas y medidas; mezquita; palacio; mensiocronología.

\begin{abstract}
The metric characterization of building materials, structures and buildings associated with various historical systems of measurement is a powerful tool for cultural and chronological affiliation, as shown by its practical application in the Royal Alcazar of Seville. The metrological analysis of various examples of Islamic architecture shows the universality of Islamic system of measurement in all the territories under its control.
\end{abstract}

Keywords: System of weights and measures; mosque; palace; mensiochronology.

Recibido: 21-07-2014. Aceptado: 16-12-2014.

\section{Copyright}

(c) 2015 CSIC. Este es un artículo de acceso abierto distribuido bajo los términos de la licencia Creative Commons Attribution-Non Commercial (by-nc) Spain 3.0. 


\section{PROPUESTA, OBJETIVOS Y MÉTODO}

Este artículo pretende profundizar en el análisis de la forma y las dimensiones de materiales de construcción, estructuras y edificios, asociados a los diferentes sistemas de medidas empleados a lo largo del tiempo desde un punto de vista cronológico y tipológico. No es en absoluto algo nuevo. Es larga la trayectoria de los estudios relacionados de un lado con la metrología ${ }^{1}$, y de otro con el análisis de las formas arquitectónicas, su geometría y modulación, vinculados a las edificaciones históricas ${ }^{2}$. Nuestra aportación en este trabajo se fundamenta en un argumento básico que puede ser de utilidad, dentro de la Arqueología de la Arquitectura, para ayudar a resolver dilemas hasta ahora controvertidos, en especial los que afectan al conjunto arquitectónico al que hacemos referencia en el título de este trabajo. Como requisito previo es necesario indicar que la función cronotipológica de los estudios formales y metrológicos adquiere desarrollo completo cuando se realizan sobre una secuencia constructiva elaborada tras el análisis arqueológico del edificio, que pueda garantizar la correcta posición del elemento dentro de la secuencia estratigráfica. Formulado de una manera simple, el tamaño y la forma son importantes en el diseño de los edificios, esenciales para cubrir las necesidades funcionales para las que fueron concebidos y consecuentes con el conocimiento geométrico y concepciones simbólicas inherentes a la cultura que los generó. En este punto el sistema de pesas y medidas es una pieza esencial y no menor; con base en él, se diseñan y ejecutan los edificios, se organizan las ciudades, se parcelan los campos, se pesan los granos, se establecen las reglas para el intercambio comercial, en definitiva, se controla la economía de un estado. Por estos motivos el control estricto del sistema de medidas es una cuestión prácticamente sagrada y, por esta razón, tiende a ser inmutable en la zona bajo dominio de un determinado estado o cultura.

El discurso que vamos a desarrollar se basa en este principio básico: todo poder político va a usar un sistema

El estudio de la metrología antigua ha sido una constante desde el surgimiento de la Arqueología científica, desde el pionero trabajo de Hultsch (1882) o Rottländer (1979) para la metrología greco-romana o, ya más cercanos, los trabajos de Vallvé (1976) sobre metrología islámica y, ante todo, debemos resaltar los de Félix Hernández (Hernández 1961, 1975), que con su método supo marcar las pautas que hoy seguimos.

2 Desde el Renacimiento y la recuperación de la obra de Vitruvio iniciaron un intenso análisis sobre la geometría aplicada a la arquitectura, una buena síntesis de los estudios geométricos sobre arquitectura antigua es el trabajo de Ruiz de la Rosa (Ruiz 1986, 1987), también para arquitectura romana Taylor (2006), Wilson Jones (2003) o Adam (2002). de pesas y medidas común a todo el territorio bajo su tutela y diferente al de sus vecinos y rivales, lo que tiene un enorme potencial para poder diferenciar cultural y cronológicamente las construcciones históricas a partir del análisis de sus dimensiones.

Es un hecho asumido que los romanos utilizaban el mismo sistema de medidas para todo el imperio, con leves diferencias achacables más a las características físicas del soporte de la regla y a la aplicación sobre el terreno del diseño proyectado que a una variabilidad del patrón de medida. La medida estándar es válida para todo el territorio con un mínimo porcentaje de incertidumbre que por lo general no sobrepasa el $1 \%$. Sin embargo, no ocurre lo mismo con los sistemas de medidas en los territorios islámicos, en los que se considera una cierta variabilidad. Félix Hernández en Córdoba (Hernández 1961, 1975), en un ejemplar trabajo en el que conjuga la información textual con el análisis directo de los elementos arquitectónicos, concluyó que el sistema de medida lineal empleado se basaba en un pie de $31,43 \mathrm{~cm}$ con un codo ordinario de $47,14 \mathrm{~cm}$ que nos sirvió de punto de partida para analizar su posible utilización en el entorno geográfico sevillano. El pie establecido por Félix Hernández se mostró muy preciso en el análisis metrológico de las construcciones islámicas de Sevilla independientemente de su datación, lo que conllevó el establecimiento, como hipótesis preliminar, de que este sistema hubiera sido común para todo el territorio andalusí. Su aplicación a diversos edificios en el territorio peninsular parecía confirmar este extremo lo que nos llevó a aventurar la idea de un sistema de medidas común a todo el Islam. Como expondremos abajo, los ejemplos que aquí analizamos parecen apuntar en esta dirección y dan cuerpo a la hipótesis de que los pilares esenciales del Islam fueron la unidad religiosa, la unidad política, la unidad lingüística, y también, la unidad económica a partir del control de los intercambios desde un único sistema de pesas y medidas. El pie árabe, en torno a los $32 \mathrm{~cm}$ (Cardarelli 2003: 76) o los 31,43 cm de Félix Hernández (Hernández 1961), parece ser válido desde Amán a Kairuán, Tinmal o para cualquiera de los territorios de Al Andalus, mostrando una posible uniformidad que contrastará con la variedad de sistemas empleados en los nacientes reinos cristianos de la Península Ibérica.

Este principio nos ofrece la oportunidad de establecer una adscripción cultural, y por tanto, en gran medida cronológica de cualquier construcción, estructura e incluso artefacto, atendiendo al sistema de medidas bajo 
el cual fue creado. Sin embargo, creo que es necesario reflexionar sobre el papel de los sistemas de medidas lineales en una sociedad y más concretamente, en el diseño y construcción de edificios. Una tendencia generalizada en los estudios sobre las dimensiones de los edificios históricos es considerar el sistema de medida como variable, de tal manera que parece una potestad del arquitecto o incluso del propio gobernante el cambiar el patrón de referencia a voluntad, quizás sin entrar a considerar las implicaciones que para la economía de un estado pudiera tener este hecho ${ }^{3}$. Aunque en un principio pudiera parecer poco relevante, el patrón de medida afecta a todo el ciclo productivo, desde la modulación de los materiales de construcción, al aparejo constructivo y con todo ello, al control de los costos. Son motivos suficientes como para pensar que un arquitecto que diseñara un edificio tendría cierta libertad para la elección de su geometría, forma, estructura y distribución; podía establecer el módulo base a partir de una serie de unidades del sistema de medida vigente pero no modificarlo. Este principio es tan significativo que los primeros cambios que podemos observar en un proceso de conquista son los referentes a los símbolos ideológicos, políticos y religiosos, y el cambio del sistema de pesas y medidas. La conquista romana supuso la implantación de un sistema de medidas común en todo el territorio bajo su control, conviviendo en algunos lugares con los sistemas locales de larga tradición (Bridger 1984; Duncan-Jones 1980). Un proceso similar puede identificarse con la implantación del sistema de medida drusiano durante la Antigüedad Tardía y época altomedieval en el norte de España (Caballero y Utrero 2005: 172). La conquista islámica pudo suponer, a tenor de los datos que aquí vamos a tratar, la sustitución del sistema romano y godo por el islámico, que posteriormente fue reemplazado durante la conquista cristiana.

Metodológicamente no siempre es fácil deducir el sistema de medida empleado; no basta sólo con dividir una medida lineal entre el valor estimado del pie. Para el análisis dimensional de edificios es necesario conocer primero la forma geométrica que sirve de base al proyecto y después aplicar la conversión al sistema de unidades de referencia, sólo en ese momento todo cobra

\footnotetext{
3 Aunque el conocimiento del sistema de medidas empleado en una construcción parta del análisis de sus dimensiones globales y parciales, usando principalmente el método estadístico, de ahí no tiene por qué derivarse la aplicación de un sistema de medidas exclusivo para el mismo o, incluso, el uso de diferentes sistemas de medidas. Aunque este principio metodológico es apropiado, los resultados pueden llevar a la consideración del edificio como ajeno y autónomo del contexto cultural y político en el que se erigió.
}

sentido. Con respecto a los materiales de construcción, la variabilidad de sus medidas obliga a un análisis estadístico para su caracterización métrica. Un problema de no fácil solución es la falta del rigor necesario en la planimetría para poder sacar conclusiones del análisis de sus dimensiones, encontrando diferentes planos de un mismo edificio con variaciones sustanciales ${ }^{4}$. Por otro lado, debemos considerar un cierto grado de incertidumbre a consecuencia de: una puesta en obra no muy precisa, a las deformaciones de las estructuras debidas a fallos estructurales o a la fatiga de los materiales por los efectos del tiempo, o a un levantamiento planimétrico no demasiado ajustado. Aun así, en los ejemplos que aquí vamos a desarrollar hemos propuestos modelos geométricos cuyo margen de error está en torno al 1\%.

El Alcázar de Sevilla es uno de los conjuntos arquitectónicos más relevantes de la arquitectura medieval española, que hace que su conocimiento se convierta en paradigma. A este fin, desde hace ya mucho tiempo, se han dedicado multitud de investigadores desde ópticas y disciplinas distintas, con estrategias metodológicas diferentes y llegando a conclusiones, muchas veces, divergentes. En $1997^{5}$ se inició un ambicioso proyecto de investigación arqueológica en los Reales Alcázares de Sevilla, con un conjunto de métodos basados en los criterios teóricos y metodológicos de la Arqueología de la Arquitectura ${ }^{6}$, que ha dado unos resultados que, en cierta medida, contradicen lo escrito hasta la fecha, especialmente desde otras disciplinas (Cómez 2007: 333-334). Nuestra incorporación a su equipo de investigación pretende seguir una vía metodológica que, con renovadas técnicas, aporte nuevos apoyos para la descripción y datación de las estructuras arqueológicas ${ }^{7}$. En primer lugar, la caracterización métrica de los materiales de construcción cuya variabilidad puede ser sensible

\footnotetext{
4 Ilustrador a este respecto es el prólogo que Alfonso Jiménez realiza al libro de Almagro sobre levantamiento arquitectónico (Almagro 2004).

5 De manera continuada desde 1997 se han abordado diferentes proyectos de investigación arqueológica que han analizado el subsuelo del Patio de la Montería y el León, al palacio de Pedro I a través de la intervención en el Patio de las Doncellas, un programa de auscultación general que ha analizado diversos puntos estratégicos para conocer la evolución del complejo arquitectónico, la puerta del Recinto I en la casa del patio Banderas 6, el subsuelo del Patio de Banderas y el palacio del primer recinto en la actividad arqueológica realizada en la casa 7-8 del Patio de Banderas (Tabales 2010).

6 Estos principios metodológicos quedaron establecidos en Sevilla por Tabales y han servido de guía a quienes nos dedicamos a esto (Tabales 2002a). 7 El análisis estadístico de las fábricas de ladrillo en Sevilla lo comenzamos en la Hacienda de Miraflores (Jiménez Hernández 2002), y posteriormente en el Patio de San Laureano de Sevilla, antiguo palacio de Hernando Colón (Arenas, Carrasco, Conlin, Jiménez y Lafuente 2004) y en Carmona, en el convento de Concepción (Carrasco y Jiménez 2008).
} 


\begin{tabular}{|c|c|c|c|c|c|c|c|c|c|c|c|c|}
\hline & Dedo & Pulgada & Palmo & Palma & Pie & Palmipié & Codo & \begin{tabular}{|c|} 
Codo \\
7 palmos
\end{tabular} & $\begin{array}{c}\text { Codo } \\
7,5 \text { palmos }\end{array}$ & $\begin{array}{l}\text { Codo } \\
2 \text { pies }\end{array}$ & 2,5 pies & Vara \\
\hline & digitus & uncia & palmus & $\begin{array}{c}\text { palmus } \\
\text { maior }\end{array}$ & pes & palmipes & cubitus & & & & gradus & \\
\hline \multirow[t]{2}{*}{ Drusiano } & 2,08 & 2,78 & 8,33 & 25 & 33,33 & 41,66 & 50 & 58,33 & 62,49 & 66,66 & 83,33 & 99,99 \\
\hline & assba & & $q a b d a$ & sibr & & & ma'muniyya & & rassasiyya & arsh & & qasab \\
\hline \multirow[t]{2}{*}{ Islámico } & 1,96 & 2,62 & 7,86 & 23,57 & 31,43 & 39,28 & 47,14 & 55 & 58,93 & 62,85 & 78,57 & 94,28 \\
\hline & digitus & uncia & palmus & $\begin{array}{c}\text { palmus } \\
\text { maior }\end{array}$ & pes & palmipes & cubitus & & & & gradus & \\
\hline Romano & 1,85 & 2,46 & 7,39 & 22,18 & 29,57 & 36,96 & 44,36 & 51,75 & 55,44 & 59,14 & 73,93 & 88,71 \\
\hline Castellano & 1,74 & 2,32 & 6,97 & 20,9 & 27,86 & 34,83 & 41,79 & 48,755 & 52,24 & 55,72 & 69,65 & 83,58 \\
\hline
\end{tabular}

Figura 1. Síntesis de las unidades y valores en centímetros de los principales sistemas de medidas de uso en la Edad Media en el entorno de Sevilla.

a dos factores: la función y la cronología. En segundo lugar, el estudio metrológico de las estructuras, su puesta en obra y aparejos, que se realizan combinando materiales en una relación precisa, lo que otorga a cada estructura una característica metrológica, variable que, a su vez, nos permite compararlas con otras estructuras. Por último, todo edificio se diseña con base en un esquema geométrico definido, trazado en unidades enteras del sistema de medida propio, lo que proporciona la posibilidad de analizar cada esquema desde una perspectiva cronológica, geográfica o cultural.

\section{NOTAS SOBRE METROLOGÍA HISTÓRICA}

Siguiendo la idea básica que aquí defendemos, la modulación, las formas y formatos se crearon según un determinado sistema de medida y su definición nos proporciona una importante herramienta para deducir el diseño original. Vamos a sintetizar en las siguientes líneas los principales sistemas de medidas que nos afectan en nuestro ámbito de estudio, sus dimensiones y relaciones entre ellos.

Los sistemas de medidas lineales anteriores a la instauración del sistema métrico decimal constan, de manera general, de una serie de unidades antropométricas, que permiten su utilización a diferentes escalas con base duodecimal, hexadecimal o vigesimal. La unidad base es el pie a partir de la cual se establecen otras con una relación equivalente entre los distintos sistemas de medidas que vamos a tratar aquí. Como podemos observar en la figura 1, un pie está compuesto de 16 dedos, 12 pulgadas ó 4 palmos menores; igualmente, existen medidas mayores como el codo, que en su forma ordinaria equivale a 1,5 pies, aunque hay una serie de variantes que iremos desarrollando a lo largo del texto.

El sistema de medida romano (Hultsch 1882) parte de un pie de $29,57 \mathrm{~cm}$, con un codo equivalente a 44,36 $\mathrm{cm}$ y con el carácter de ser común para todo el territorio imperial aunque pudo convivir con otros sistemas locales. El pie drusiano, según Higinio Gromático ${ }^{8}$, era $1 / 8$ mayor que el pie romano, resultando $33,3 \mathrm{~cm}$. El pie castellano tiene una equivalencia de $27,86 \mathrm{~cm}^{9}$.

Acerca del sistema de medida islámico parece existir una cierta confusión entre las diferentes unidades de medidas. En Al Andalus están documentados dos tipos de codos que en realidad no son sistemas de medida distintos sino diferentes unidades del mismo sistema, el codo común o mamuni de 24 dedos y el codo rassasí de 30 dedos, o lo que es lo mismo, un codo normal de 6 palmos menores y otro mayor de 7,5 palmos, establecido en Córdoba por Umar b. Faray al Rassas a tenor de lo dicho por Ibn Luyun (Eguaras 1988: 206). Sus dimensiones quedaron definidas por Félix Hernández en 47,14 $\mathrm{cm}$ para el codo común y en $58,93 \mathrm{~cm}$ para el rassasí. El codo rassasí es, en realidad, una medida que establecía una equivalencia clara con el sistema romano equivaliendo a dos pies romanos con precisión de un decimal.

\footnotetext{
De Conditionibus Agrorum 76.10 (Thulin 1913: 86).

9 La diversidad de medidas en España queda de manifiesto en la tabla de correspondencias de pesas y medidas de cara a la implantación del sistema métrico decimal, publicado en el número 6763 de la Gaceta de Madrid de 28 de diciembre de 1852.
} 


\begin{tabular}{|c|c|c|c|c|c|c|c|c|c|c|}
\hline & Dedo & Pulgada & Palmo & Palma & Pie & Palmipié & Codo & Codo 7 p & $\begin{array}{c}\text { Codo } 7,5 \\
\text { p. }\end{array}$ & $\begin{array}{c}\text { Codo } 2 \\
\text { pies }\end{array}$ \\
\hline Codo 2 pies & & & & & & & & & & 1 \\
\hline Codo 7,5 p. & & & & & & & & & 1 & $11 / 15$ \\
\hline Codo 7 p & & & & & & & & 1 & $11 / 14$ & $11 / 7$ \\
\hline Codo & & & & & & & 1 & $11 / 6$ & $11 / 4$ & $11 / 3$ \\
\hline Palmipié & & & & & & 1 & $11 / 5$ & $12 / 5$ & $11 / 2$ & $13 / 5$ \\
\hline Pie & & & & & 1 & $11 / 4$ & $11 / 2$ & $13 / 4$ & $17 / 8$ & 2 \\
\hline Palma & & & & 1 & $11 / 3$ & $12 / 3$ & 2 & $21 / 3$ & $21 / 2$ & $22 / 3$ \\
\hline Palmo & & & 1 & 3 & 4 & 5 & 6 & 7 & $7 \quad 1 / 2$ & 8 \\
\hline Pulgada & & 1 & 3 & 9 & 12 & 15 & 18 & 21 & $221 / 2$ & 24 \\
\hline Dedo & 1 & $11 / 3$ & 4 & 12 & 16 & 20 & 24 & 28 & 30 & 32 \\
\hline
\end{tabular}

Figura 2. Relación entre las unidades principales de los sistemas de medidas analizados en el texto.

\begin{tabular}{|c|c|c|c|c|c|c|c|c|c|}
\hline & Castellano & Romano & Islámico & Drusiano & & Castellano & Romano & Islámico & Drusiano \\
\hline Drusiano & $5 / 6$ & $8 / 9$ & $15 / 16$ & 1 & Drusiano & 0,84 & 0,89 & 0,94 & 1 \\
\hline Islámico & $8 / 9$ & $15 / 16$ & 1 & $1+1 / 16$ & Islámico & 0,89 & 0,94 & 1 & 1,06 \\
\hline Romano & $15 / 16$ & 1 & $1+1 / 16$ & $1+1 / 8$ & Romano & 0,94 & 1 & 1,06 & 1,13 \\
\hline Castellano & 1 & $1+1 / 16$ & $1+1 / 8$ & $1+1 / 5$ & Castellano & 1 & 1,06 & 1,13 & 1,2 \\
\hline
\end{tabular}

Figura 3. Relación aritmética entre los distintos sistemas de medidas.

Para la mezquita de Tudela, sin embargo, se ha propuesto un codo de entre $52 \mathrm{~cm}$ y $54 \mathrm{~cm}$ (Navas, Martínez, Cabañero y Lasa 1995: 102) y para la de Zaragoza, dos codos distintos de $55 \mathrm{~cm}$ y $53 \mathrm{~cm}$ (Hernández Vera 2004: 81) para las dos principales fases detectadas en la mezquita. Para la mezquita de Tudela y la última fase de Zaragoza no parece obligado un nuevo codo de $52-54 \mathrm{~cm}$, puesto que las medidas reseñadas en metros, son perfectamente traducibles a codos mamunies según los valores expresados por Hernández Jiménez; así se indica que la longitud total del edificio es de 71 metros equivalentes a 135 codos de $53 \mathrm{~cm}$ ó 150 codos mamunies; la longitud del patio de 23,66 metros la hacen equivaler a 45 codos, siendo 50 codos mamunies; y la anchura total del edificio de 32 metros equivalentes a 100 pies derivados del codo mamuní (31,43 metros). El codo de $55 \mathrm{~cm}$ es un codo de 7 palmos del sistema de medida islámico frente a los 6 palmos del codo mamuní y los 7,5 del rassasí.

Por tanto, las medidas otorgadas por Félix Hernández parecen representar un único sistema de medida válido, con leves variaciones, para todo el territorio andalusí y como sostenemos en este trabajo, común o generalizado para todos los territorios islámicos.

Estos sistemas convivieron durante gran parte de estos dos milenios y llegaron a establecer entre sí unas equivalencias que mostramos en la figura 3 . De esta forma, un pie romano equivale a 17 dedos castellanos, el islámico a 17 dedos romanos y el drusiano a 17 dedos islámicos; un codo mamuní equivale a 27 dedos castellanos (una relación 24/27) y un pie drusiano es una octava parte mayor del romano, es decir, 18 dedos romanos. 


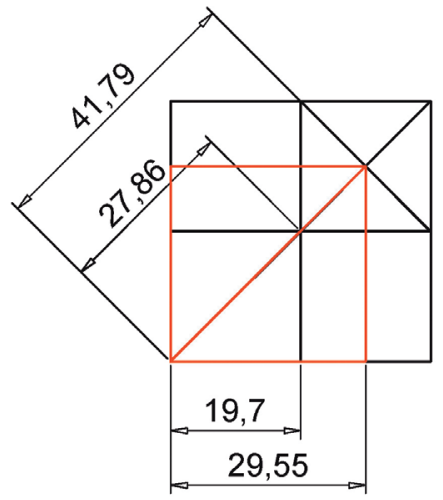

Relaciones del pie y codo castellanos

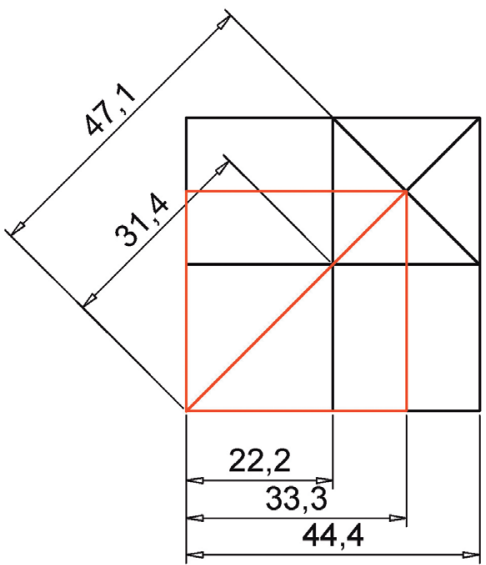

Relaciones del codo mamuni y su pie derivado

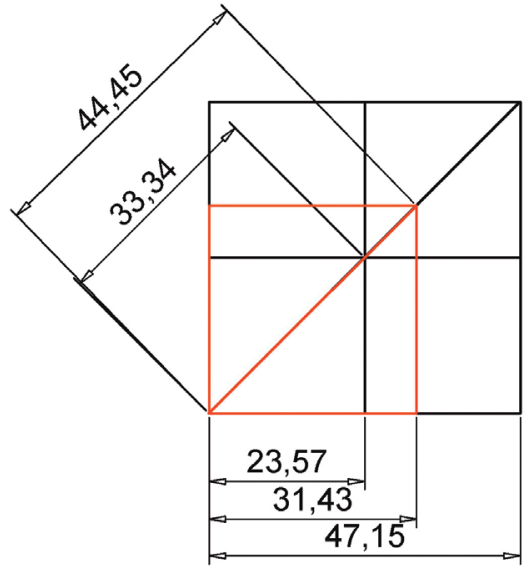

Relaciones del codo romano y su pie derivado

Figura 4. Relación geométrica entre los sistemas de medidas analizados.

Siguiendo con equivalencias geométricas, el codo castellano equivale a la diagonal de un cuadrado de un pie romano de lado; el codo romano es la diagonal de un cuadrado de un pie islámico de lado y lo mismo ocurre con el codo normal islámico respecto al pie drusiano, con una precisión de un decimal. Estas relaciones lineales permitieron durante la convivencia de estos sistemas una rápida conversión de unidades de un sistema al otro facilitando las transacciones.

\section{MENSIOCRONOLOGÍA: ANÁLISIS ESTADÍSTICO DE ELEMENTOS MODULARES}

La mensiocronología (Mannoni y Milanese 1988) debe ser considerada como una técnica para la caracterización metrológica de materiales constructivos modulares con la finalidad de contextualizar cultural y cronológicamente las estructuras de las que forman parte ${ }^{10}$.

Aunque en origen la finalidad principal de su empleo fue la de datar los edificios con un procedimiento fácil de ejecutar, las implicaciones del método obligan a ampliar los objetivos y niveles de análisis de las dimensiones del material de construcción. Así, éste va a estar directamente relacionado con la tradición cultural del lugar de fabricación, con las técnicas de construcción,

\footnotetext{
${ }_{10}$ Para la experiencia en España consúltese (Quirós 1996; Altarriba, Guillén, Rojo, Martí, y Guzmán 2001)
}

con el tipo de obra, con el promotor de las mismas, con las materias primas disponibles en el entorno de la ciudad; tendrá implicaciones sociales, económicas y, por supuesto, estará directamente relacionado con el sistema de medida empleado por la comunidad que los fabrica. Por tanto, la mensiocronología trasciende a la datación como objetivo único.

Si hay algo común a todas las construcciones humanas eso son las matemáticas. Todo en cualquier tiempo y lugar está sujeto a patrones, a estrictas reglas que garantizan la eficiencia de las estructuras y que permiten controlar los costos de las mismas. De este modo, podemos considerar un muro como una fórmula en la que sus componentes son factores interrelacionados, el grosor del muro, el tamaño de los sillares, de los ladrillos, de las vigas, de los cajones de encofrar, la forma de aparejar, hasta el diseño de los edificios de los que forman parte.

Con estos antecedentes, el diseño del método debe buscar una caracterización precisa y objetiva de las dimensiones del objeto así como de su utilización o puesta en obra. Además, debe poder aplicarse a cualquier material o parte estructural modular.

\section{El método estadístico}

La estadística descriptiva es la única forma de caracterizar métricamente unos materiales de construcción, especialmente irregulares como el ladrillo, de tal forma que puedan compartirse los valores obtenidos por 
los distintos investigadores. Aunque el método puede y debe emplearse para todos los elementos constructivos modulados es particularmente necesario en el caso de una pieza como el ladrillo. No es nuevo que el tamaño del ladrillo es importante a la hora de datar construcciones; su referencia ha estado presente en las publicaciones de las excavaciones urbanas y todos los investigadores conocemos, de una manera general, los módulos de ladrillos de los distintos períodos históricos. Sin embargo, esos valores no permiten una precisión cronológica suficientemente válida como para competir con los sistemas tradicionales de datación, cuya causa puede buscarse en que existen algunos elementos que dificultan y distorsionan nuestra capacidad para caracterizar métricamente las piezas:

- En primer lugar, los ladrillos tras moldearse son sometidos al fuego que provoca su contracción y da lugar a una variabilidad en sus dimensiones.

- Es común que aparezcan en una estructura piezas fragmentadas.

- El ladrillo es un material duradero y caro por lo que su reutilización en obras muy posteriores a la fecha de su fabricación es una práctica habitual.

- Aunque el formato está regulado oficialmente ${ }^{11}$, la picaresca está presente dando lugar a una merma en su masa que igualmente distorsiona el análisis de sus dimensiones.

- En último lugar, los arqueólogos usamos nuestro sistema métrico decimal, redondeando los valores a éste, de tal forma que obtenemos ladrillos de $28 \mathrm{~cm}$ x14 $\mathrm{cm}, 30 \mathrm{~cm} \times 15 \mathrm{~cm}$ que como veremos no son medidas muy ajustadas.

\section{La tabla de referencia}

El objetivo principal es la elaboración de una tabla de referencia donde se muestren los distintos formatos de ladrillos a lo largo del tiempo. Generalmente, se ha tendido a representar los valores mensiocronológicos en una curva, lo que induce a pensar en un proceso evolutivo continuo que si bien puede ser válido para un lapso temporal concreto, no creemos que refleje correctamente la complejidad de los formatos a lo largo de los distintos períodos históricos. En primer lugar, la competencia municipal en la regulación de los sistemas

\footnotetext{
11 Ibn Abdun, en su tratado de hisba, establece la obligatoriedad de la existencia de patrones que regulen el tamaño de las gavetas de los ladrillos (Lévi-Provençal y García 1998: 113).
}

de pesas y medidas hace que la escala de referencia sea local y difícilmente puede ser válida para otros lugares; en segundo lugar, no ha existido siempre un único formato de manera que como ocurre en época islámica, conviven una serie amplia de tipos fabricados para una función específica.

Para la elaboración de la tabla es necesario establecer una base obtenida sobre edificios que estén bien datados y que abarquen todo el rango cronológico. Posteriormente, se toman los datos, como a continuación detallaremos, teniendo presente que las estructuras analizadas deben haber sido objeto de un análisis arqueológico de los paramentos que certifique la cronología propuesta. Finalmente, es conveniente contrastar los datos obtenidos con otros edificios de la misma datación.

Consideramos necesario que la tabla abarque distintos períodos históricos, para poder establecer mejor el contraste entre distintas etapas culturales y mostrar las inercias o herencias de los modelos precedentes, incluyendo la época Romana, la Tardoantigüedad, Edad Media, Moderna y Contemporánea.

La tabla es un proceso retroalimentado, es necesaria para datar nuevas muestras que, a su vez, se incorporarán a la tabla para contrastarla, modificarla o complementarla. Una vez establecida, con la identificación de los distintos formatos, hay que analizar qué variables son más sensibles a la evolución cronológica, que, por supuesto, no serán generales para todos los periodos.

Por último, consideramos necesario vincular las medidas del formato de la pieza con su puesta en obra de forma que lo podamos relacionar con el aparejo y con el sistema de medidas bajo el que se creó.

\section{Toma de datos}

El procedimiento ideal para la toma de datos es registrar todas las dimensiones de cada una de las piezas. Sin embargo, esto obligaría a desmontar las estructuras para medir sus componentes, hecho que generalmente no es posible y casi nunca deseable. Esta obviedad sirve para justificar el procedimiento que proponemos basado en la medición de las piezas a partir de los paramentos.

El primer paso para una correcta toma de datos es elegir un paramento realizado con fábrica regular, con piezas igualmente regulares y cuya interpretación estratigráfica avale que se ha realizado en un único momento. Con este presupuesto, tomaremos un mínimo de 30 mediciones, aunque cuanto mayor sea la muestra mayor será la precisión de los siguientes valores: 
- Soga $=1$

- Tizón = a

- Grosor $=\mathrm{h}$

- Soga más la junta o llaga $=1+11$

- Tizón más la junta $=a+11$

- Hilada (grosor más el tendel $)=$ hil

Las mediciones deben tener precisión al milímetro y estar tomadas con instrumentos que minimicen el factor humano. Para ello el calibrador, pie de rey o forcípula son sin duda los mejores instrumentos para la medición. Las cintas métricas o flexómetros permiten precisiones ajustadas pero, como hemos podido comprobar, el registro de la información va a depender mucho de la persona que ejecuta el trabajo.

\section{Depuración de los datos}

Analizamos en primer lugar la muestra obtenida para conocer la tendencia central y la dispersión de los datos. Los principales valores que debemos considerar son el promedio, la mediana, la moda, la curtosis, el coeficiente de asimetría y el intervalo de confianza. En una distribución normal, las medidas de tendencia central (media, mediana y moda) serán coincidentes o tendrán valores muy próximos. La curtosis nos indicará el grado de dispersión de la muestra centrado en cero, de tal forma que un valor próximo a cero indicará una curva mesocúrtica; un número positivo mostrará una curva más concentrada o leptocúrtica; un valor negativo reflejará una muestra más dispersa o platicúrtica. El coeficiente de asimetría reflejará la distribución de la muestra, de tal forma que un valor próximo a cero indicará una curva simétrica, números negativos una curva con más valores a la izquierda y positivos con más ítems a la derecha. El intervalo de confianza, que generalmente establecemos en el $95 \%$, indica un valor que sumado y restado a la media englobaría al 95\% de los valores esperados.

\section{Expresión de los datos}

Una vez depurados los datos, estos se expondrán textualmente indicando la media y el intervalo de confianza al $95 \%$, de 1, a, h, hil, $1+11$ y a +11 .

De los datos estadísticos primarios podremos obtener los siguientes valores derivados, que serán de gran utilidad para comparar los distintos formatos de ladrillo y su puesta en obra:

- Volumen $=1 * \mathrm{a} * \mathrm{~h}$

- Tendel $=$ Hil $-\mathrm{h}$
- Junta prevista $=1-2 * a$

- Junta ejecutada en soga $=111-1$

- Junta ejecutada en tizón = all - a

- Proporción entre soga y tizón $=1 / a$

El volumen nos ofrece una síntesis de los tres valores principales para el ladrillo y suele ser muy sensible en los casos analizados a la variación diacrónica, ya que refleja las oscilaciones en cualquiera de sus variantes aun manteniéndose constante las otras dos. El tamaño del tendel ilustra sobre el aparejo constructivo y se vincula a la composición del mortero. Las juntas previstas y ejecutadas nos permiten relacionar si el formato del ladrillo se ajusta al aparejo ejecutado, en ese caso, estos valores debían ser coincidentes. La proporción entre la soga y el tizón es también significativa y complementaria de la información anterior, así por ejemplo, para los aparejos habituales en ladrillo en época medieval y moderna, la soga debe ser dos veces el tizón más el ancho de la llaga, es decir una proporción mayor a dos. En el caso de algunos ladrillos almohades analizados la proporción uno a dos, conlleva una evidente irregularidad en el aparejo.

Para la expresión gráfica se emplearán los histogramas para representar los cuatro valores principales de cada muestra, L (longitud o soga), A (ancho o tizón), H (grosor) y Hil (hilada).

\section{Muestras}

Aportamos unas series representativas que abarcan un amplio marco cronológico entre los siglos XI-XII y XIX, principalmente obtenidas en Los Reales Alcázares de Sevilla, en el Patio de San Laureano y la Hacienda Miraflores de Sevilla, ordenadas cronológicamente.

\section{Islámicas}

\section{Muestra 1}

Localización: Antemuro de la muralla islámica almohade del Callejón del Agua.

\section{Tabla de resultados:}

$\mathrm{L}=28,78+/-0,25 ; \mathrm{A}=14,41+/-0,19 ; \mathrm{H}=5+/-0,16$; Hil $=8,04+/-0,23$

\section{Valoración de la muestra:}

La muestra se realizó sobre 40 ítems de un paramento que estratigráficamente era monofásico y no mostraba indicios de restauración por lo que quedaba garantizado que las muestras correspondían a piezas uniformes y pertenecientes al momento de construcción del antemuro de la muralla. 


\begin{tabular}{|c|c|c|c|c|c|c|}
\hline & $\boldsymbol{L}$ & $\boldsymbol{A}$ & $\boldsymbol{H}$ & Lll & All & HIl \\
\hline Media & 28,78 & 14,41 & 5,00 & 29,89 & 15,55 & 8,04 \\
\hline Error típico & 0,12 & 0,10 & 0,08 & 0,29 & 0,13 & 0,11 \\
\hline Mediana & 28,85 & 14,40 & 5,00 & 30,00 & 15,45 & 8,00 \\
\hline Moda & 29,00 & 14,40 & 5,00 & 30,00 & 15,00 & 8,00 \\
\hline Desviación estándar & 0,78 & 0,61 & 0,52 & 1,82 & 0,83 & 0,71 \\
\hline Varianza de la muestra & 0,61 & 0,37 & 0,27 & 3,30 & 0,68 & 0,50 \\
\hline Curtosis & 1,39 & 0,54 & 0,36 & 18,51 & 0,29 & 2,22 \\
\hline Coeficiente de asimetría & $-0,50$ & $-0,30$ & 0,91 & $-3,52$ & 0,28 & 0,36 \\
\hline Rango & 4,00 & 2,80 & 2,00 & 12,00 & 4,00 & 4,00 \\
\hline Mínimo & 26,50 & 12,90 & 4,30 & 20,50 & 13,50 & 6,00 \\
\hline Máximo & 30,50 & 15,70 & 6,30 & 32,50 & 17,50 & 10,00 \\
\hline Cuenta & 40 & 40 & 40 & 40 & 40 & 40 \\
\hline Nivel de confianza $(95,0 \%)$ & 0,25 & 0,19 & 0,16 & 0,58 & 0,26 & 0,23 \\
\hline
\end{tabular}

Figura 5. Resumen estadístico de la muestra 1.

Los resultados estadísticos reflejan esta apreciación indicando una coincidencia casi exacta entre los valores de tendencia central. Las curvas obtenidas son leptocúrticas, mostrando una significativa agrupación de los valores en torno al valor central y con una asimetría irrelevante.

De los valores obtenidos podemos concluir que el formato de la pieza es rectangular de tal forma que la anchura es exactamente la mitad de la longitud. Metrológicamente la longitud es equivalente a 11 pulgadas $(28,8$ $\mathrm{cm}$ ) del sistema de medida islámico (pie de $31,43 \mathrm{~cm}$ ); la anchura es justo la mitad de la longitud; el grosor es equivalente a 2,5 dedos $(4,9 \mathrm{~cm})$ y la hilada corresponde a un palmo islámico $(7,86 \mathrm{~cm})$.

\section{Muestra 2}

\section{Localización:}

La muestra 2 fue obtenida durante una intervención arqueológica efectuada en el solar $n^{\circ} 3$ de la Calle Santo Tomás sobre un lienzo de la muralla almohade que conecta el Alcázar con la llamada torre de Abdl Aziz.

Tabla de resultados:

$\mathrm{L}=28,78+/-0,12 ; \mathrm{A}=14,4+/-0,09 ; \mathrm{H}=4,9+/-0,04$; Hil $=7,8+/-0,08$

\begin{tabular}{|l|r|r|r|r|r|r|}
\hline & $\boldsymbol{L}$ & $\boldsymbol{A}$ & $\boldsymbol{H}$ & $\boldsymbol{L}$ & \multicolumn{1}{c|}{ All } & \multicolumn{1}{l|}{ Hil } \\
\hline Media & 28,78 & 14,40 & 4,91 & 30,69 & 16,11 & 7,80 \\
\hline Error típico & 0,06 & 0,04 & 0,02 & 0,09 & 0,07 & 0,04 \\
\hline Mediana & 28,90 & 14,40 & 4,90 & 30,50 & 16,00 & 7,80 \\
\hline Moda & 28,50 & 14,40 & 4,90 & 30,40 & 16,00 & 8,00 \\
\hline Desviación estándar & 0,59 & 0,55 & 0,29 & 0,89 & 0,90 & 0,68 \\
\hline Varianza de la muestra & 0,35 & 0,30 & 0,09 & 0,78 & 0,82 & 0,46 \\
\hline Curtosis & 3,63 & 3,54 & 0,64 & 1,57 & 1,03 & 0,72 \\
\hline Coeficiente de asimetría & $-1,09$ & $-0,73$ & $-0,11$ & 0,87 & 0,23 & 0,64 \\
\hline Rango & 3,70 & 3,90 & 1,80 & 5,00 & 5,90 & 4,10 \\
\hline Mínimo & 26,30 & 12,10 & 4,00 & 28,90 & 13,40 & 6,20 \\
\hline Máximo & 30,00 & 16,00 & 5,80 & 33,90 & 19,30 & 10,30 \\
\hline Cuenta & 94 & 162 & 252 & 90 & 160 & 251 \\
\hline Nivel de confianza (95,0\%) & 0,12 & 0,09 & 0,04 & 0,19 & 0,14 & 0,08 \\
\hline
\end{tabular}

Figura 6. Resumen estadístico de la muestra 2. 


\section{Valoración de la muestra:}

La muestra se obtuvo entre unos 90 y 252 ítems, variación que se explica por la dificultad de detectar sogas completas en el aparejo de ladrillo de los machones de la muralla. Por ese motivo se tomaron más referencias sobre grosor e hilada que sobre sogas o tizones.

La muralla presentaba múltiples rehechos producto de distintas intervenciones de reparación del paramento $\mathrm{y}$, aunque las medidas fueron tomadas tras un estricto análisis estratigráfico que permitió seleccionar las unidades estratigráficas correspondientes al momento de construcción de la muralla, es posible que en la muestra se incluyeran ejemplares no pertenecientes a la misma. Además, el lienzo está construido principalmente con tapial, reservándose el ladrillo para elementos muy puntuales como machones de refuerzo o la torre adosada a la muralla, elementos que no suelen tener mucha extensión por lo que es frecuente que se utilicen piezas fragmentadas.

A pesar de lo indicado los resultados validan los de la muestra 1. Los valores de tendencia central son prácticamente idénticos y sólo se diferencia en que la muestra 2 es algo más leptocúrtica y una asimetría negativa algo mayor.

\section{Muestra 3}

\section{Localización:}

Patio de Banderas Casa 7-8, obtenida en el muro de separación de la alcoba oeste y la sala principal durante la reciente intervención arqueológica (Tabales y Vargas 2014).

\section{Tabla de resultados:}

$\mathrm{L}=27,01+/-0,25 ; \mathrm{A}=13,22+/-0,44 ; \mathrm{H}=2,74+/-0,21$; Hil $=5,78+/-0,27$

\section{Valoración de la muestra:}

El espacio muestreado era demasiado pequeño como para obtener un número suficiente de piezas para realizar todas las mediciones. Aunque el número de datos tomados no llega al que consideramos necesario, hecho que se refleja en las cifras del intervalo de confianza, es representativa de un formato pequeño que encontramos igualmente en el Palacio de la Casa de la Contratación, en la nave norte y en las casas documentadas en el patio de banderas, fechadas en el siglo XI, y demolidas para la construcción del primer recinto del Alcázar (Tabales 2013: 99-101). Esta muestra se corresponde con un formato de ladrillo islámico de 10 pulgadas $(26,19 \mathrm{~cm})$ de manera que el tizón es de 5 pulgadas y la soga sean 10 pulgadas más la llaga, de manera que la relación $1 / a$ es de 2,04 . Su grosor equivale a 1 pulgada y la hilada es de 3 dedos $(5,88 \mathrm{~cm})$.

\section{Bajomedieval cristiano \\ Muestra 4 \\ Localización:}

La muestra se obtuvo en el sótano del Palacio Gótico de Alfonso X.

\begin{tabular}{|l|c|c|c|c|}
\hline & $\boldsymbol{L}$ & $\boldsymbol{A}$ & $\boldsymbol{H}$ & $\boldsymbol{H I L}$ \\
\hline Media & 27,01 & 13,22 & 2,74 & 5,78 \\
\hline Error típico & 0,11 & 0,19 & 0,09 & 0,12 \\
\hline Mediana & 26,85 & 13,45 & 2,80 & 5,80 \\
\hline Moda & 26,80 & 13,70 & 2,80 & 5,90 \\
\hline Desviación estándar & 0,35 & 0,61 & 0,29 & 0,38 \\
\hline Varianza de la muestra & 0,12 & 0,37 & 0,08 & 0,15 \\
\hline Curtosis & $-0,09$ & 1,12 & 5,30 & $-0,50$ \\
\hline Coeficiente de asimetría & 0,88 & $-1,32$ & $-1,98$ & 0,19 \\
\hline Rango & 1,10 & 1,80 & 1,10 & 1,20 \\
\hline Mínimo & 26,60 & 11,90 & 2,00 & 5,20 \\
\hline Máximo & 27,70 & 13,70 & 3,10 & 6,40 \\
\hline Cuenta & 10 & 10 & 10 & 10 \\
\hline Nivel de confianza (95,0\%) & 0,25 & 0,44 & 0,21 & 0,27 \\
\hline
\end{tabular}

Figura 7. Resumen estadístico de la muestra 3. 


\begin{tabular}{|l|c|c|c|c|c|c|}
\hline & $\boldsymbol{L}$ & $\boldsymbol{A}$ & $\boldsymbol{H}$ & $\boldsymbol{L}$ Hll & Hll \\
\hline Media & 28,17 & 13,79 & 4,51 & 29,79 & 15,66 & 7,72 \\
\hline Error típico & 0,14 & 0,14 & 0,08 & 0,23 & 0,25 & 0,10 \\
\hline Mediana & 28,00 & 13,70 & 4,40 & 29,90 & 15,50 & 7,60 \\
\hline Moda & 28,00 & 13,40 & 4,00 & 29,50 & 16,30 & 7,50 \\
\hline Desviación estándar & 0,85 & 0,83 & 0,48 & 1,40 & 1,52 & 0,62 \\
\hline Varianza de la muestra & 0,72 & 0,68 & 0,23 & 1,97 & 2,31 & 0,39 \\
\hline Curtosis & 0,96 & $-0,18$ & $-0,50$ & 16,25 & 0,40 & 0,54 \\
\hline Coeficiente de asimetría & 0,46 & 0,02 & 0,15 & $-3,26$ & 0,37 & 0,25 \\
\hline Rango & 4,20 & 3,40 & 2,00 & 8,90 & 6,60 & 2,80 \\
\hline Mínimo & 26,20 & 12,00 & 3,50 & 22,90 & 12,80 & 6,40 \\
\hline Máximo & 30,40 & 15,40 & 5,50 & 31,80 & 19,40 & 9,20 \\
\hline Cuenta & 37 & 37 & 37 & 37 & 37 & 37 \\
\hline Nivel de confianza(95,0\%) & 0,28 & 0,28 & 0,16 & 0,47 & 0,51 & 0,21 \\
\hline
\end{tabular}

Figura 8. Resumen estadístico de la muestra 4.

Tabla de resultados:

$\mathrm{L}=28,17+/-0,28 ; \mathrm{A}=13,79+/-0,28 ; \mathrm{H}=4,51+/-0,16$; Hil $=7,72+/-0,21$

\section{Valoración de la muestra:}

Los valores fueron tomados en el sótano del Palacio Gótico. Los paramentos aparecen libres de revestimiento pero en la mayor parte de su superficie las llagas están rejuntadas y se aprecian restauraciones parciales.

Aunque las condiciones no fueron las idóneas la toma de muestras se realizó tras un análisis estratigráfico preliminar desechándose las zonas conflictivas.

En general, las curvas adquieren una presencia normal, mesocúrtica y una leve asimetría positiva. Los valores centrales tienen valores muy próximos si no idénticos.

La muestra indica un cambio en el formato con respecto a las dos primeras muestras almohades. En primer lugar, la longitud es 2,04 veces la anchura, es decir, dos anchos más la llaga, formato que permite un mejor aparejo de las piezas. En cuanto a la metrología, la anchura es medio pie castellano $(13,93 \mathrm{~cm})$, la longitud equivale a un pie más una llaga; el grosor de la pieza es 2,5 dedos castellanos $(4,55 \mathrm{~cm})$ y la hilada una undécima parte de la vara castellana $(7,59 \mathrm{~cm})$.

\section{Muestra 5}

\section{Localización:}

Palacio de Don Fadrique, Convento de Santa Clara de Sevilla.
Tabla de resultados:

$\mathrm{L}=28,27+/-0,11 ; \mathrm{A}=13,77+/-0,07 ; \mathrm{H}=4,98+/-0,07$; $\mathrm{Hil}=7,62+/-0,24$

\section{Valoración de la muestra:}

Los valores fueron tomados en el palacio de Don Fadrique, actual Convento de Santa Clara de Sevilla construido poco después de la conquista de Sevilla (Oliva y Tabales 2011) con el fin de contrastar los resultados obtenidos en el Palacio Gótico del Alcázar de Sevilla.

Los paramentos estaban picados en el momento de la toma de datos sin que existiera ningún obstáculo para la correcta toma de datos que, por premura de tiempo, quedó circunscrita a los valores principales.

En general, las curvas adquieren una presencia normal, mesocúrtica y simétrica. Los valores centrales tienen valores muy próximos.

La muestra ratifica el cambio en el formato con respecto a las muestras almohades, siendo coincidentes con las obtenidas en el Palacio Gótico. Sólo el grosor del ladrillo presenta un valor medio superior cercano a $0,5 \mathrm{~cm}$ que, no obstante, no afecta al grosor de la hilada que se mantiene en los mismos términos. La anchura es medio pie castellano $(13,93 \mathrm{~cm})$, la longitud equivale a un pie más una llaga; el grosor de la pieza es próximo a los 3 dedos castellanos $(5,22$ $\mathrm{cm})$ y la hilada una undécima parte de la vara castellana $(7,59 \mathrm{~cm})$. 


\begin{tabular}{|l|r|r|r|c|}
\hline & $\boldsymbol{L}$ & $\boldsymbol{A}$ & $\boldsymbol{H}$ & Hil \\
\hline Media & 28,27 & 13,77 & 4,98 & 7,62 \\
\hline Error típico & 0,06 & 0,03 & 0,03 & 0,12 \\
\hline Mediana & 28,25 & 13,80 & 5,00 & 7,50 \\
\hline Moda & 28,00 & 13,70 & 5,00 & 7,00 \\
\hline Desviación estándar & 0,28 & 0,21 & 0,22 & 0,75 \\
\hline Varianza de la muestra & 0,08 & 0,05 & 0,05 & 0,56 \\
\hline Curtosis & 0,34 & $-0,38$ & 3,62 & $-0,12$ \\
\hline Coeficiente de asimetría & 0,83 & $-0,35$ & $-1,29$ & 0,10 \\
\hline Rango & 1,10 & 0,90 & 1,10 & 3,50 \\
\hline Mínimo & 27,90 & 13,30 & 4,20 & 6,00 \\
\hline Máximo & 29,00 & 14,20 & 5,30 & 9,50 \\
\hline Cuenta & 26,00 & 41,00 & 41,00 & 41,00 \\
\hline Nivel de confianza (95,0\%) & 0,11 & 0,07 & 0,07 & 0,24 \\
\hline
\end{tabular}

Figura 9. Resumen estadístico de la muestra 5.

\section{Muestra 6}

\section{Localización:}

Puerta entre el patio del León y patio de la Montería.

Tabla de resultados:

$\mathrm{L}=29,14+/-0,21 ; \mathrm{A}=14,28+/-0,19 ; \mathrm{H}=5,30+/-0,17$; Hil $=8,07+/-0,26$

\section{Valoración de la muestra:}

Los datos obtenidos de la puerta entre los patios del León y de la Montería muestran una curva normal prácticamente mesocúrtica y simétrica. Los valores de tendencia central son muy próximos salvo en la longitud con una discrepancia entre la moda $(28,5)$ y la media $(29,13)$ y la mediana $(29,05)$ y algo menos en la anchura, grosor e hilada. Estas diferencias pueden ser debidas a que las piezas pudieron adaptarse a los machones de las puertas (con piezas recortadas) o a la inserción de piezas reutilizadas.

De todas formas, asistimos a un cambio de formato con un aumento significativo del tamaño de las piezas. La proporción entre longitud y anchura es de 2,04 lo que indica que ésta es dos anchos más una llaga, valor idéntico al de la muestra del Palacio Gótico.

Metrológicamente la longitud y anchura son mayores al pie castellano sin que podamos establecer una correlación clara entre sus medidas y los valores originales. El grosor de las piezas aumenta hasta acercarse a los 3 dedos y la hilada se aproxima a la décima parte de la vara castellana $(8,4)$.

\begin{tabular}{|l|r|r|r|r|r|r|}
\hline & $\boldsymbol{L}$ & $\boldsymbol{A}$ & $\boldsymbol{H}$ & $\boldsymbol{L} \boldsymbol{H}$ & $\boldsymbol{H} \boldsymbol{H}$ \\
\hline Media & 29,14 & 14,28 & 5,30 & 30,49 & 15,71 & 8,07 \\
\hline Error típico & 0,10 & 0,09 & 0,09 & 0,13 & 0,12 & 0,13 \\
\hline Mediana & 29,05 & 14,30 & 5,35 & 30,40 & 15,80 & 8,05 \\
\hline Moda & 28,50 & 14,50 & 5,50 & 30,00 & 16,20 & 8,20 \\
\hline Desviación estándar & 0,66 & 0,60 & 0,54 & 0,80 & 0,74 & 0,82 \\
\hline Varianza de la muestra & 0,44 & 0,35 & 0,30 & 0,63 & 0,55 & 0,68 \\
\hline Curtosis & $-0,27$ & $-0,15$ & 0,04 & $-0,89$ & 0,84 & 0,22 \\
\hline Coeficiente de asimetría & $-0,03$ & $-0,09$ & $-0,09$ & 0,24 & 0,17 & 0,60 \\
\hline Rango & 3,00 & 2,50 & 2,50 & 3,00 & 3,70 & 3,80 \\
\hline Mínimo & 27,50 & 13,00 & 4,00 & 29,00 & 14,10 & 6,50 \\
\hline Máximo & 30,50 & 15,50 & 6,50 & 32,00 & 17,80 & 10,30 \\
\hline Cuenta & 40 & 40 & 40 & 40 & 40 & 40 \\
\hline Nivel de confianza (95,0\%) & 0,21 & 0,19 & 0,17 & 0,25 & 0,24 & 0,26 \\
\hline
\end{tabular}

Figura 10. Resumen estadístico de la muestra 6. 


\begin{tabular}{|l|r|r|r|r|r|r|}
\hline & $\boldsymbol{L}$ & $\boldsymbol{A}$ & $\boldsymbol{H}$ & $\boldsymbol{L} \boldsymbol{L}$ & $\boldsymbol{A L L}$ & $\boldsymbol{H} \boldsymbol{L}$ \\
\hline Media & 29,20 & 14,61 & 5,09 & 31,00 & 16,14 & 8,47 \\
\hline Error típico & 0,06 & 0,04 & 0,03 & 0,35 & 0,07 & 0,06 \\
\hline Mediana & 29,20 & 14,60 & 5,10 & 31,35 & 16,00 & 8,50 \\
\hline Moda & 29,00 & 14,20 & 5,20 & 31,00 & 16,00 & 8,70 \\
\hline Desviación estándar & 0,52 & 0,32 & 0,26 & 3,15 & 0,68 & 0,57 \\
\hline Varianza de la muestra & 0,27 & 0,10 & 0,07 & 9,90 & 0,46 & 0,32 \\
\hline Curtosis & 2,66 & $-0,98$ & 2,03 & 72,32 & 0,89 & 2,59 \\
\hline Coeficiente de asimetría & 0,75 & 0,07 & 0,95 & $-8,25$ & 0,68 & 0,69 \\
\hline Rango & 3,30 & 1,20 & 1,50 & 29,20 & 3,80 & 3,70 \\
\hline Mínimo & 28,00 & 14,00 & 4,60 & 3,70 & 14,50 & 7,00 \\
\hline Máximo & 31,30 & 15,20 & 6,10 & 32,90 & 18,30 & 10,70 \\
\hline Cuenta & 82 & 82 & 82 & 82 & 82 & \\
\hline Nivel de confianza(95,0\%) & 0,11 & 0,07 & 0,06 & 0,69 & 0,15 & 0,13 \\
\hline
\end{tabular}

Figura 11. Resumen estadístico de la muestra 7.

\section{Muestra 7}

\section{Localización:}

Sala del Billar y Sala de Fumar en la planta alta del palacio del Rey Don Pedro, en los paramentos del Salón de Embajadores.

Tabla de resultados:

$\mathrm{L}=29,2$ +/- 0,11; $\mathrm{A}=14,61+/-0,07 ; \mathrm{H}=5,09$ +/- 0,06; Hil $=8,47+/-0,13$

\section{Valoración de la muestra:}

Esta muestra, obtenida de los paramentos que conforman la qubba principal del palacio de Pedro I, confirma el cambio de formato ya identificado en la muestra anterior. La longitud supera los $29 \mathrm{~cm}$ con un valor próximo al pie romano; el tizón de la mitad de la soga mientras que el grosor supera los $5 \mathrm{~cm}$, cerca de 3 dedos castellanos y la hilada equivale a la 1/10 de la vara castellana.

\section{Edad Moderna}

Muestra 8

Capilla Jesús (1506)

Tabla de resultados:

$\mathrm{L}=29,57+/-0,20 ; \mathrm{A}=14,35+/-0,13 ; \mathrm{H}=4,86+/-0,09$; Hil $=7,45+/-0,30$

\begin{tabular}{|l|c|c|c|c|}
\hline & $\boldsymbol{L}$ & $\boldsymbol{A}$ & $\boldsymbol{H}$ & Hil \\
\hline Media & 29,57 & 14,35 & 4,86 & 7,45 \\
\hline Error típico & 0,10 & 0,06 & 0,04 & 0,15 \\
\hline Mediana & 29,50 & 14,20 & 5,00 & 7,50 \\
\hline Moda & 29,50 & 14,00 & 5,00 & 7,00 \\
\hline Desviación estándar & 0,54 & 0,34 & 0,23 & 0,80 \\
\hline Varianza de la muestra & 0,29 & 0,12 & 0,05 & 0,64 \\
\hline Curtosis & $-0,58$ & 0,60 & $-0,51$ & 0,48 \\
\hline Coeficiente de asimetría & $-0,09$ & 1,01 & $-0,70$ & 0,50 \\
\hline Rango & 2,00 & 1,20 & 0,90 & 3,50 \\
\hline Mínimo & 28,50 & 14,00 & 4,40 & 6,00 \\
\hline Máximo & 30,50 & 15,20 & 5,30 & 9,50 \\
\hline Cuenta & 30 & 30 & 30 & 30 \\
\hline Nivel de confianza (95,0\%) & 0,20 & 0,13 & 0,09 & 0,30 \\
\hline
\end{tabular}

Figura 12. Resumen estadístico de la muestra 8. 


\section{Valoración de la muestra:}

Esta muestra se realizó sobre los paramentos exteriores de la Capilla de Jesús en la Puerta de Jerez de Sevilla, muy próxima al Alcázar, aprovechando una renovación de su enlucido.

Los valores centrales son prácticamente coincidentes y muy parecidos a los obtenidos en el Alcázar pertenecientes a las obras de Pedro I, lo que muestra una continuidad del nuevo formato aunque con algunas variaciones.

La longitud es de $29,57 \mathrm{~cm}$, un pie romano exacto y su anchura es de $14,35 \mathrm{~cm}$ de forma que la relación 1/a es de 2,06. El grosor del ladrillo es algo inferior, cercano a las 2 pulgadas castellanas, y la hilada es de 7,45, equivalente a $1 / 11$ de la vara castellana.

\section{Muestra 9}

Hacienda de Miraflores ${ }^{12}$

Muestra obtenida en el Señorío (ca. 1500).

\section{Tabla de resultados:}

$\mathrm{L}=29,83+/-0,10 ; \mathrm{A}=14,43+/-0,14 ; \mathrm{H}=4,41+/-0,09$; Hil $=8,24+/-0,20$

12 (Jiménez 2002; Lara, López, Jiménez y Romero 1998)
Valoración de la muestra:

La muestra tiene una tendencia normal y no evidencia desviaciones significativas de los valores centrales. Sigue el curso de las muestras anteriores, desde Pedro I, con una longitud algo mayor cercana a los $30 \mathrm{~cm}$ y un grosor ligeramente inferior, aún así, la hilada llega a los $8,24 \mathrm{~cm}$ valor muy próximo a la décima parte de la vara castellana, otorgando un mayor protagonismo al tendel en el aparejo.

\section{Muestra 10}

Torre molino (XVI-XVII)

El molino de aceite de la Hacienda de Miraflores se construyó en un momento incierto entre los siglos XVI y XVII con posterioridad a la erección del señorío de la misma.

Tabla de resultados:

$\mathrm{L}=29,33+/-0,13 ; \mathrm{A}=14,01+/-0,12 ; \mathrm{H}=4,78+/-0,10$; Hil $=8,42+/-0,18$

\section{Valoración de la muestra:}

Muestra normal que sigue la tendencia de los ejemplos anteriores con un formato de soga próxima al valor de un pie

\begin{tabular}{|l|c|c|c|c|c|c|}
\hline & \multicolumn{1}{|c|}{$\boldsymbol{A}$} & $\boldsymbol{A}$ & $\boldsymbol{H}$ & $\boldsymbol{L} \boldsymbol{c}$ & $\boldsymbol{A l l}$ & Hil \\
\hline Media & 29,83 & 14,43 & 4,41 & 31,56 & 16,06 & 8,24 \\
\hline Error típico & 0,05 & 0,07 & 0,05 & 0,12 & 0,10 & 0,10 \\
\hline Mediana & 29,90 & 14,40 & 4,50 & 31,45 & 16,00 & 8,25 \\
\hline Moda & 30,00 & 14,20 & 4,20 & 31,60 & 15,50 & 7,50 \\
\hline Desviación estándar & 0,27 & 0,37 & 0,25 & 0,64 & 0,57 & 0,54 \\
\hline Varianza de la muestra & 0,07 & 0,14 & 0,06 & 0,41 & 0,32 & 0,29 \\
\hline Curtosis & 0,67 & 0,66 & $-0,18$ & 1,17 & $-0,81$ & $-0,10$ \\
\hline Coeficiente de asimetría & $-0,59$ & 0,10 & 0,36 & 0,86 & 0,70 & 0,43 \\
\hline Rango & 1,10 & 1,80 & 1,00 & 2,90 & 1,80 & 2,10 \\
\hline Mínimo & 29,20 & 13,50 & 4,00 & 30,40 & 15,40 & 7,50 \\
\hline Máximo & 30,30 & 15,30 & 5,00 & 33,30 & 17,20 & 9,60 \\
\hline Cuenta & 30 & 30 & 30 & 30 & 30 & 30 \\
\hline Nivel de confianza (95,0\%) & 0,10 & 0,14 & 0,09 & 0,24 & 0,21 & 0,20 \\
\hline
\end{tabular}

Figura 13. Resumen estadístico de la muestra 9. 


\begin{tabular}{|l|r|r|r|r|r|r|}
\hline & $\boldsymbol{L}$ & $\boldsymbol{A}$ & $\boldsymbol{H}$ & $\boldsymbol{L}$ & \multicolumn{1}{c|}{ All } & \multicolumn{1}{c|}{ Hil } \\
\hline Media & 29,33 & 14,01 & 4,78 & 31,19 & 15,90 & 8,42 \\
\hline Error típico & 0,07 & 0,06 & 0,05 & 0,17 & 0,13 & 0,09 \\
\hline Mediana & 29,35 & 14,00 & 4,75 & 31,00 & 15,85 & 8,30 \\
\hline Moda & 29,00 & 14,00 & 5,00 & 31,00 & 15,50 & 8,00 \\
\hline Desviación estándar & 0,36 & 0,33 & 0,26 & 0,93 & 0,69 & 0,47 \\
\hline Varianza de la muestra & 0,13 & 0,11 & 0,07 & 0,87 & 0,48 & 0,22 \\
\hline Curtosis & 0,10 & 0,09 & $-0,35$ & 2,21 & 0,84 & $-0,14$ \\
\hline Coeficiente de asimetría & $-0,30$ & $-0,39$ & $-0,01$ & 0,57 & $-0,21$ & 0,58 \\
\hline Rango & 1,50 & 1,40 & 1,10 & 5,00 & 3,20 & 1,90 \\
\hline Mínimo & 28,50 & 13,20 & 4,20 & 29,00 & 14,00 & 7,60 \\
\hline Máximo & 30,00 & 14,60 & 5,30 & 34,00 & 17,20 & 9,50 \\
\hline Cuenta & 30 & 30 & 30 & 30 & 30 & 30 \\
\hline Nivel de confianza (95,0\%) & 0,13 & 0,12 & 0,10 & 0,35 & 0,26 & 0,18 \\
\hline
\end{tabular}

Figura 14. Resumen estadístico de la muestra 10.

romano, un grosor en torno a las dos pulgadas y una hilada correspondiente a la décima parte de una vara castellana.

\section{Colegio de San Laureano.}

Este emblemático edificio, antiguo palacio de Hernando Colón (Arenas, Carrasco, Conlin, Jiménez, y Lafuente 2004), fue objeto de una intensa campaña de actividades arqueológicas en la que realizamos, por primera vez, un análisis exhaustivo de las fábricas de ladrillos y cuyos resultados, ya publicados, sintetizamos en el siguiente cuadro que sirve para contrastar y completar la secuencia de formatos en Sevilla hasta época Contemporánea.

\section{Valoración de las muestras:}

La intervención arqueológica en San Laureano nos permitió obtener un registro muy completo de los formatos de ladrillo de la Edad Moderna y Contemporánea, contrastando los valores obtenidos en las muestras coetáneas anteriores.

En general, se mantiene el formato iniciado en tiempos de Pedro I hasta el siglo XVII, aunque los valores de esta centuria los ponemos en cuarentena porque sospechamos que las obras de esta época reaprovecharon los ladrillos que se salvaron de la total ruina del palacio colombino $\mathrm{y}$, a mitad del siglo XVIII, asistimos a un nuevo cambio de formato con piezas sustancialmente más pequeñas, equivalentes a un pie castellano que se aparejan en hiladas que suponen la duodécima parte de una vara, tendencia que se sigue acusando a lo largo del siglo XIX y principios del XX.

\begin{tabular}{|c|r|r|r|r|r|r|r|r|}
\hline Fecha & Largo & Ancho & Grosor & Hilada & Llaga & Tendel & Volumen & \multicolumn{1}{|c|}{ L } \\
\hline $\mathbf{1 5 2 6}$ & 29,46 & 14,15 & 4,78 & 8,17 & 1,16 & 3,39 & 2,08 \\
\hline $\mathbf{1 5 9 5}$ & 29,74 & 14,42 & 5,25 & 8,22 & 0,90 & 2,97 & 2251,20 & 2,06 \\
\hline $\mathbf{1 7 0 0}$ & 29,15 & 14,01 & 4,70 & 8,34 & 1,13 & 3,64 & 1917,82 & 2,08 \\
\hline $\mathbf{1 7 0 0}$ & 29,78 & 14,53 & 4,71 & 8,63 & 0,72 & 3,92 & 2037,93 & 2,05 \\
\hline $\mathbf{1 7 5 0}$ & 28,65 & 13,79 & 4,14 & 6,79 & 1,07 & 2,64 & 1636,50 & 2,08 \\
\hline $\mathbf{1 8 0 0}$ & 27,49 & 13,34 & 4,77 & 6,15 & 0,80 & 1,37 & 1750,82 & 2,06 \\
\hline $\mathbf{1 8 4 8}$ & 27,07 & 13,13 & 4,53 & 6,15 & 0,81 & 1,62 & 1609,68 & 2,06 \\
\hline $\mathbf{1 9 0 0}$ & 26,54 & 12,98 & 4,26 & 6,40 & 0,58 & 2,14 & 1466,64 & 2,04 \\
\hline
\end{tabular}

Figura 15. Tabla de los formatos de ladrillos del Colegio de San Laureano (Sevilla). 


\section{Repertorio de formatos de ladrillos en Sevilla entre los siglos XI al XX}

En general, los datos presentan una estructura muy coherente. Hemos conseguido certificar que los ladrillos empleados en estructuras islámicas utilizan un formato sensiblemente diferente del que posteriormente utilizarán los cristianos tanto en forma como en dimensiones. Evidentemente, la base metrológica es el sistema islámico con un codo normal o mamuní de $47,14 \mathrm{~cm}$ y su pie equivalente de $31,43 \mathrm{~cm}$.

Hasta la fecha la primera constancia que tenemos de fabricación estandarizada de ladrillos en Sevilla es de época Taifa. En el siglo XI el formato documentado es de 10 pulgadas más la llaga de longitud y 5 pulgadas de ancho; su grosor es de 1 pulgada y se apareja en hiladas de 3 dedos.

Para el período almohade se han documentado una mayor diversidad de piezas que resumimos en la siguiente tabla:

El más común y caracterizado por nuestros análisis mensiocronológicos es el de 11 pulgadas con grosor de 2,5 dedos puesto en obra en hiladas de 1 palmo o la duodécima parte de 3 pies. Es también muy habitual el formato de 10 pulgadas que se puede presentar con un grosor de 1 pulgada o de 2,5 dedos, dado que los distintos formatos pueden adquirir diferentes grosores, vinculables con su puesta en obra. De esta manera, la hilada más habitual es la de 1 palmo de altura, lo que significa cuatro ladrillos por cada pie de paramento o 12 hiladas equivalentes a un cajón de tapial de 3 pies, el más común. No obstante, las hiladas pueden ser sensiblemente menores, equivalentes a 5 hiladas por pie o a 11 por cajón de tapial de 2,5 pies, también muy común entre las fábricas islámicas.

La conquista cristiana introdujo severos cambios en el formato de las piezas. En primer lugar, la gran variedad de ladrillos islámicos se reduce a un solo formato. $\mathrm{Su}$ base metrológica será el sistema de medida castellano con un pie de $27,86 \mathrm{~cm}$, dando lugar a ladrillos rectangulares con una anchura de 0,5 pies y una longitud dos veces el ancho más una llaga, con un grosor de 2,5 ó 3 dedos y una puesta en obra de la undécima parte de la vara castellana (equivalente a 11 hiladas por cajón de tapial de 1 vara castellana).

Con Pedro I se produce un gran cambio en el formato iniciado con la conquista cristiana con piezas de mayores dimensiones que superan incluso a los ladrillos almohades de 11 pulgadas. Este nuevo formato adquiere una correspondencia con el pie romano o con el aragonés que aún mantenía la tradición imperial; no encontramos una explicación convincente salvo el intento de reunificación de los sistemas de medidas en el sistema romano en tiempos de Alfonso X (Vallvé 1976: 341).

Lo cierto es que este módulo seguirá vigente con algunas variaciones a lo largo de los siglos XIV, XV, XVI y XVII. En el siglo XVI se observan los mayores ladrillos de toda la secuencia con longitudes próximas a los $30 \mathrm{~cm}$ (17 dedos) y anchuras similares a las vistas para los ladrillos almohades, los grosores superan los 3 dedos y la hilada se mantiene de manera constante en la décima parte de la vara castellana, aunque no son raros los casos de hiladas equivalentes a un onceavo de vara, sobre todo entre los siglos XV-XVI.

En el siglo XVIII asistimos a un cambio de la tendencia y los ladrillos se harán menores, descendiendo sobre todo el grosor de las piezas y aparejándolos en hiladas más pequeñas. El ancho será 0,5 pies, la longitud dos veces el ancho y una llaga y el grosor llega a bajar hasta los 2 dedos, situándose la hilada hasta un doceavo de la vara castellana.

Esta tendencia se acrecienta durante el siglo XIX cuyos ladrillos tienen una longitud de 1 pie mientras la anchura se reduce a la mitad del pie menos media llaga. La hilada baja hasta ser un treceavo de la vara.

Con esta primera serie de resultados esbozamos el esquema de la evolución de los ladrillos en Sevilla desde los siglos XI-XII hasta principios del siglo XX. Es evidente que estas muestras deben contrastarse con otras que certifiquen los formatos propuestos. Para época islámica necesitamos completar el repertorio y corroborar el empleo de un formato único durante el siglo XI y

\begin{tabular}{|l|l|}
\hline Formatos & Grosores \\
\hline Ladrillo de $5 \times 2 \times 1$ palmos: $39,3 \times 15,71 \times 7,86 \mathrm{~cm}$ & 1 pulgada $(2,62 \mathrm{~cm})$ \\
\hline Ladrillo de $4 \times 2$ palmos $/ 1$ pie: $31,42 \times 15,71 \mathrm{~cm}$ & $2 \operatorname{dedos}(3,92 \mathrm{~cm})$ \\
\hline Ladrillo de 11 pulgadas: $28,8 \times 14,4 \mathrm{~cm}$ & $2,5 \operatorname{dedos}(4,9 \mathrm{~cm})$ \\
\hline Ladrillo de 10 pulgadas: $26,2 \times 13,1 \mathrm{~cm}$ & $3 \operatorname{dedos}(5,88 \mathrm{~cm})$ \\
\hline Ladrillo de 3 palmos $/ 9$ pulgadas: $23,57 \times 11,76 \mathrm{~cm}$ & 1 palmo $(7,86)$ \\
\hline
\end{tabular}

Figura 16. Formatos de ladrillos de época islámica en Sevilla. 
diferente de los usados en época almohade, lo que facilitaría un instrumento de gran utilidad para la distinción cronológica entre edificios de estas etapas históricas. Los primeros momentos de la conquista cristiana son claramente identificados por el empleo de un formato de ladrillos distinto a los almohades precedentes. Esperamos avanzar en la definición de los tipos de ladrillo usados entre los siglos XIV y XVII y poder precisar las cronologías a pesar de que se utilice la misma caja.

Además, estos valores sólo son válidos, en principio, para la ciudad de Sevilla, lo que haría deseable que la experiencia se repitiera en otros lugares con una metodología compatible que nos permitiera analizar de manera conjunta esta información.

\section{ANÁLISIS METROLÓGICO DE ESTRUCTURAS}

De la misma manera que podemos caracterizar las dimensiones de los materiales de construcción, vincularlos a un sistema de medida específico y datarlos, podemos hacerlo con estructuras individualizadas: muros, arcos, torres, ventanas, puertas y todo el repertorio tipológico de elementos estructurales. Estos tienen, además de una geometría que es la que habitualmente se utiliza para establecer analogías con fines cronológicos, unas características métricas particulares que abren la posibilidad de vincularlas a un sistema de medida específico y con ello a una cultura generadora. En numerosas ocasiones estructuras indefinidas cronológicamente, al carecer de elementos característicos, pueden ser encuadradas cronológicamente a partir de sus dimensiones. Los arcos de herradura son una forma característica de la arquitectura islámica que, no obstante, se utilizó en época cristiana con formas tan parecidas a las originarias que ha dado lugar a no pocas adscripciones erróneas que podrían quedar resueltas atendiendo al estudio de sus dimensiones.

En estructuras como los muros la relación entre los distintos elementos, materiales y aparejos genera una fórmula característica que puede servir para crear catálogos cronotipológicos de manera que, por ejemplo, lienzos de muralla con los mismos elementos y aparejos, relacionados entre sí según la misma proporción probablemente sean sincrónicos; al contrario, fábricas que parecen homogéneas pueden corresponder a momentos diferentes, construidos con base en otros diseños, con una razón entre elementos distinta.

Traemos como ejemplo la composición de un lienzo de muralla de la calle Santo Tomás de Sevilla, la que une la Puerta de los Leones con la llamada torre de Abdl Aziz. El lienzo fue analizado durante una intervención arqueológica realizada en el solar $n^{0} 3$ de la calle Santo Tomás ${ }^{13}$, lo que nos dio la oportunidad de estudiarlo en profundidad. La muralla está realizada en tapial con algunos machones de ladrillo, conservando el almenado; tiene adosada una torre construida con aparejo de ladrillo y sillarejo reforzando las esquinas.

13 Intervención arqueológica preventiva dirigida por Patricia Bachiller en 2008.

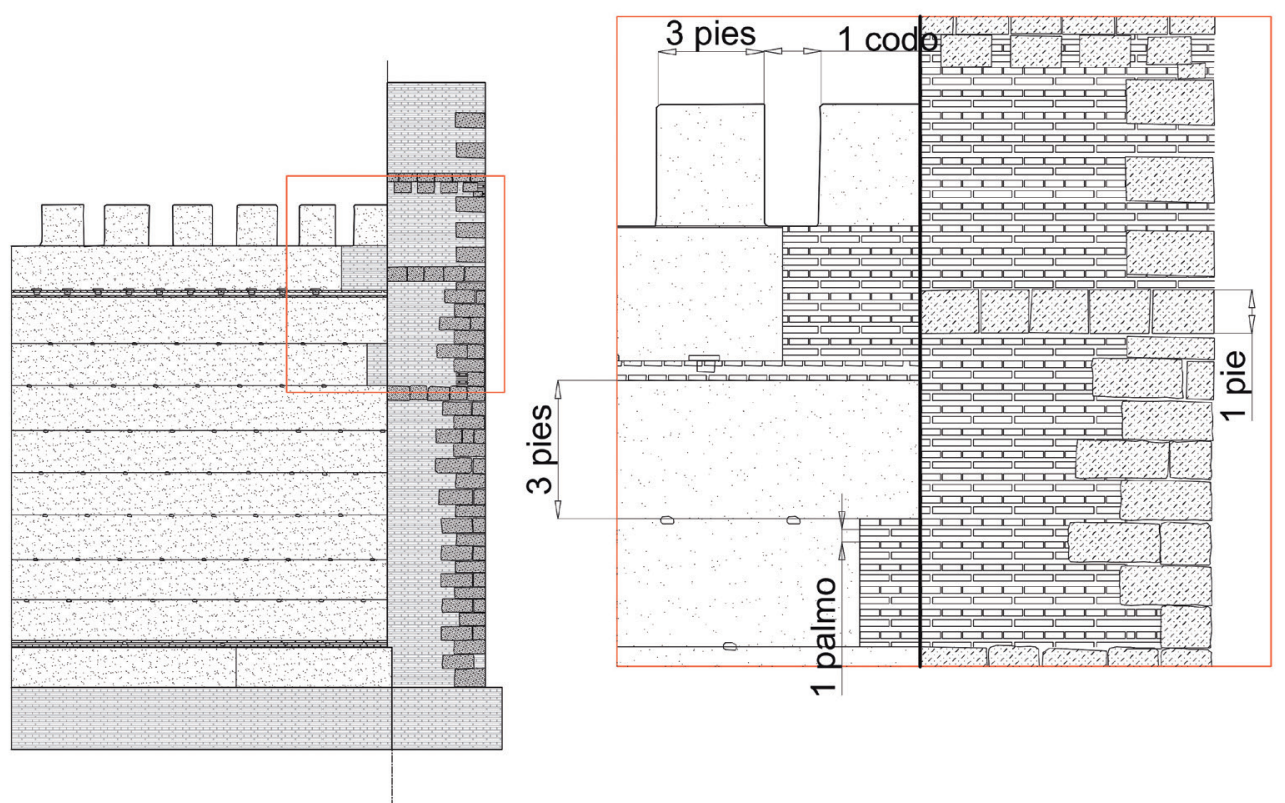

Figura 17. Alzado del lienzo de muralla de la calle Santo Tomás no 3 de Sevilla y acotación de sus elementos en unidades islámicas. 
Metrológicamente la altura del paramento sobre la cimentación es de 10 cajones de tapia exceptuando el almenado; cada caja de tapia tiene una altura de 3 pies $(94,3 \mathrm{~cm})$ que se acompaña de machones de ladrillos aparejados con hiladas de 1 palmo de altura, lo que implica que a cada cajón corresponden 12 hiladas de ladrillo. Adosado al lienzo hay una torre realizada en ladrillo con una hilada de 1 palmo, con refuerzos de sillarejos en las esquinas que tienen, de media, 1 pie de altura, es decir, 1 sillarejo cada cuatro hiladas de ladrillo. El almenado tiene también una característica metrológica; los merlones son estructuras cuadradas de 3 pies de lado, salvo los próximos a la torre que reducen ligeramente su anchura para ajustarse al espacio restante, separados por un espacio estrecho de 1 codo. Esta forma característica de construir es propia de este tramo de muralla y diferente de otros visibles en el entorno del alcázar lo que nos abre la expectativa de poder diferenciarlos por su composición metrológica y establecer una secuencia cronológica de sus momentos de construcción.

Aún pendiente de un análisis pormenorizado, existen tramos de muralla datados en época islámica que emplean ladrillos de formato de 10 pulgadas o cuyos tapiales se encofraron en cajones de 2,5 pies de altura $(78 \mathrm{~cm})^{14}$; almenado con un diseño y tamaños diferentes que son sensibles tanto a la cronología como a cuestiones poliorcéticas. Con respecto a las fábricas cristianas bajomedievales las diferencias métricas son tan sustanciales que, junto a sus características formales, nos permiten una distinción nítida entre ellas. De esta manera, los tapiales castellanos suelen adoptar una caja de una vara castellana de altura $(83,58 \mathrm{~cm})$ mientras que los islámicos alternan entre los $94 \mathrm{~cm}$ ( 3 pies) o los $78 \mathrm{~cm}$ (2,5 pies).

\section{ANÁLISIS METROLÓGICO DE EDIFICIOS}

Pasando a un nivel superior en la escala de la construcción podemos intentar vincular culturalmente un edificio a partir del sistema de medida bajo el que fue diseñado y construido. Durante este proceso de análisis que, en principio, estaba destinado a diferenciar las construcciones cristianas de sus precedentes islámicos cuyas analogías formales ofrecían dudas en su adscripción, fuimos encontrando similitudes formales y métricas que indicaban una uniformidad en las construcciones islámicas más allá de su ubicación geo-

\footnotetext{
14 Esta diversidad de formatos fueron tipificadas por Graciani y Tabales (2008: 137) denominándolos módulo bajo, inferior a $80 \mathrm{~cm}$, y módulo alto entre $85 \mathrm{~cm}$ y $95 \mathrm{~cm}$ que a su vez asocian al uso del codo rassasí o mamuní respectivamente para las tapias islámicas.
}

gráfica o temporal. Posiblemente, la hipótesis más relevante derivada de este proceso sea la uniformidad del sistema de medida en todos los territorios del Islam, hipótesis que se sustenta en los casos que ahora presentamos pero que sin duda deberá corroborarse en análisis más profundos. Las formas de los edificios también ofrecen similitudes que van más allá del territorio y del tiempo y que deben relacionarse con las concepciones ideológicas y religiosas, especialmente cuando nos referimos a las mezquitas y los palacios.

\section{Análisis metrológico aplicado a algunas mezquitas representativas}

El estudio del diseño los edificios históricos a partir del sistema de medidas de sus constructores da sentido a las formas, permite obtener modelos que sirvan de analogía para el estudio de otros edificios y estructuras, atestigua la extensión geográfica del sistema de medidas, así como también constituye una importante herramienta para establecer el marco cronológico de las construcciones.

Un serio apoyo al uso común del sistema de medidas lineal en todo el territorio de dominio islámico podemos observarlo en el análisis de algunas mezquitas representativas creadas en los primeros momentos del Islam como son la Cúpula de la Roca y la Gran Mezquita de Damasco.

Qubba al-Sakhra fue construida por el califa abd alMalik y terminada en el año 691/72 H. Su diseño se basa en tres polígonos regulares concéntricos, un octógono crea la fachada del edificio, otro menor intermedio divide las galerías y finalmente, un círculo interior que delimita la roca y sustenta su característica cúpula dorada. La relación entre estos elementos no es constante sino derivada de un sencillo desarrollo geométrico que conecta todas sus partes.

El diseño nace de una circunferencia de 120 pies islámicos de diámetro $(37,7 \mathrm{~m})$ en la que se circunscribe el octógono que delimita el paramento exterior de la arcada intermedia. Circunscribiendo un cuadrado a este círculo y una circunferencia a este cuadrado creamos la fachada mediante la inscripción de un octógono en el círculo exterior; así, las circunferencias que delimitan la fachada y la arcada interior tienen una relación de $\sqrt{2}(1,4142)$. Para delimitar el anillo interior se unen mediante líneas los vértices opuestos del octógono de fachada que generan un octógono en el que se inscribe la circunferencia que limita el paramento interior de la arcada que sostiene la cúpula ${ }^{15}$. Este análisis se ha realizado sobre el plano acotado de Creswell.

\footnotetext{
Este esquema sigue en líneas generales la traza propuesta por Mauss (1888: fig. 7)
} 


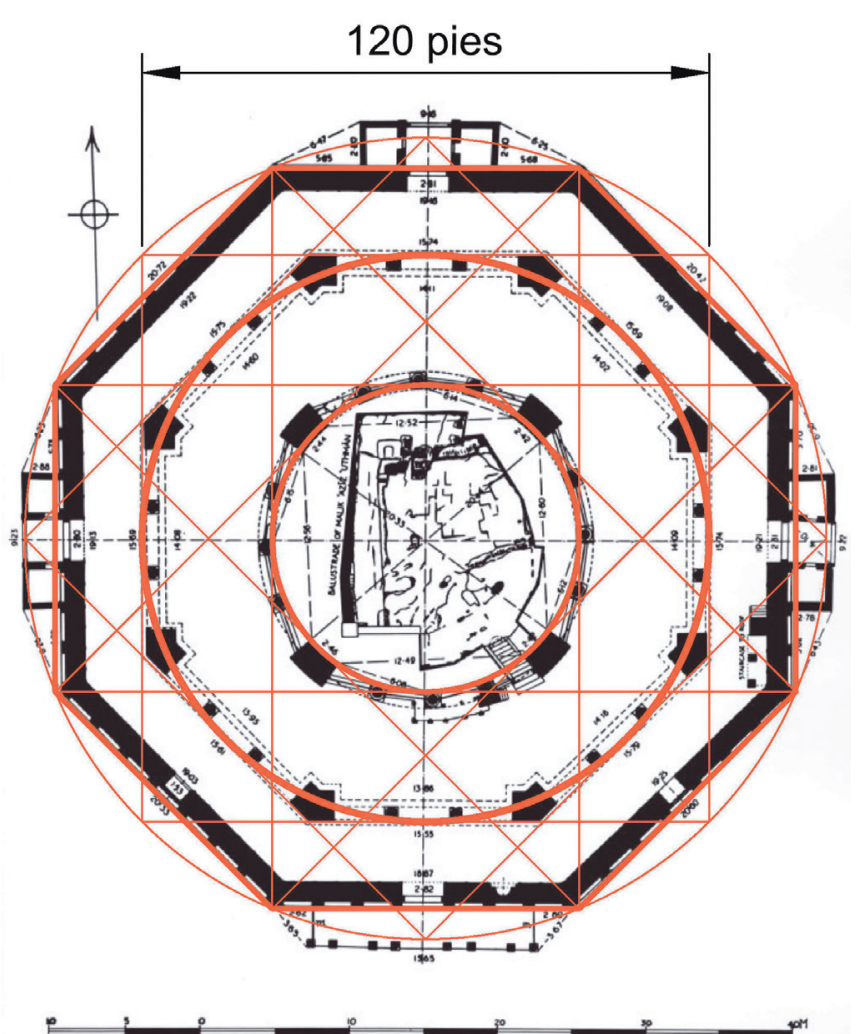

Figura 18. Análisis geométrico en pies islámicos de la Cúpula de la Roca en Jerusalén sobre plano de Creswell (Archnet.org).

La Gran Mezquita de Damasco representa un modelo que se va a repetir en la larga expansión del territorio del Islam. Este edificio va a marcar unas pautas que encontraremos en otras mezquitas, trascendiendo a las etapas iniciales del desarrollo de la arquitectura islámica. La mezquita fue construida durante el reinado del califa al Walid entre 705-706 y 715/87-88 y $96 \mathrm{H}$ y constituye uno de los primeros ejemplos de arquitectura monumental en el mundo islámico (Flood 2001: cap. 1). En primer lugar, hay que destacar que el sistema de medida empleado para el diseño de este edificio es el mismo descrito por Félix Hernández. La forma geométrica que sirve de base es un rectángulo cuyos lados están relacionados en una razón de $\sqrt{2}$, teniendo presente que se parte del cálculo de la capacidad del edificio, es decir, la longitud interior de la mezquita es equivalente a 300 pies $(94,3 \mathrm{~m})$ ó 200 codos mamunies ó 160 codos rassasies, mientras que la anchura es la diagonal de un cuadrado de 300 pies de lado, o lo que es lo mismo, $300 * \sqrt{ } 2$ (424,3 pies ó $133,3 \mathrm{~m})$. A pesar de aprovechar un recinto romano, diseñado con un sistema de medida romano, el nuevo patrón de medida encuentra su equivalencia con el imperial a través del codo rassa$s i$, equivalente a 2 pies romanos. De esta forma, los 300 pies islámicos traducen los 320 romanos. Su forma es quizás más relevante que su métrica ya que la relación $\sqrt{2}$ entrará a formar parte de algunas de las mezquitas que vamos a analizar.

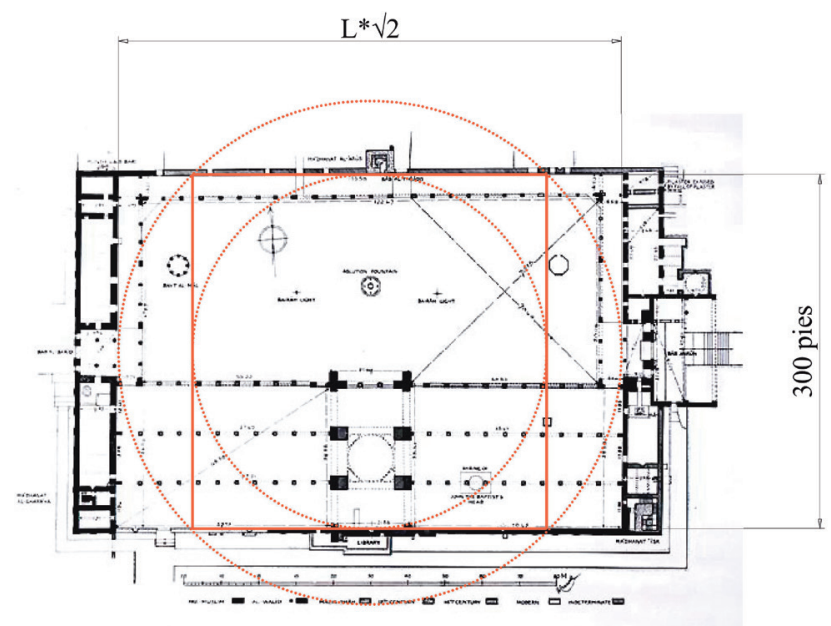

Figura 19. Análisis geométrico en pies islámicos de la Gran Mezquita de Damasco sobre plano de Creswell (Archnet.org).

En Amán, la mezquita de la ciudadela fue excavada y documentada en 1997 por un equipo dirigido por Antonio Almagro (Almagro y Jiménez 2000) que permitió la restitución total de la planta. La mezquita, construida en el primer tercio del siglo VIII, tiene una forma cuadrada con una ligera deformación en su esquina noreste. Este peculiar diseño, que será reproducido

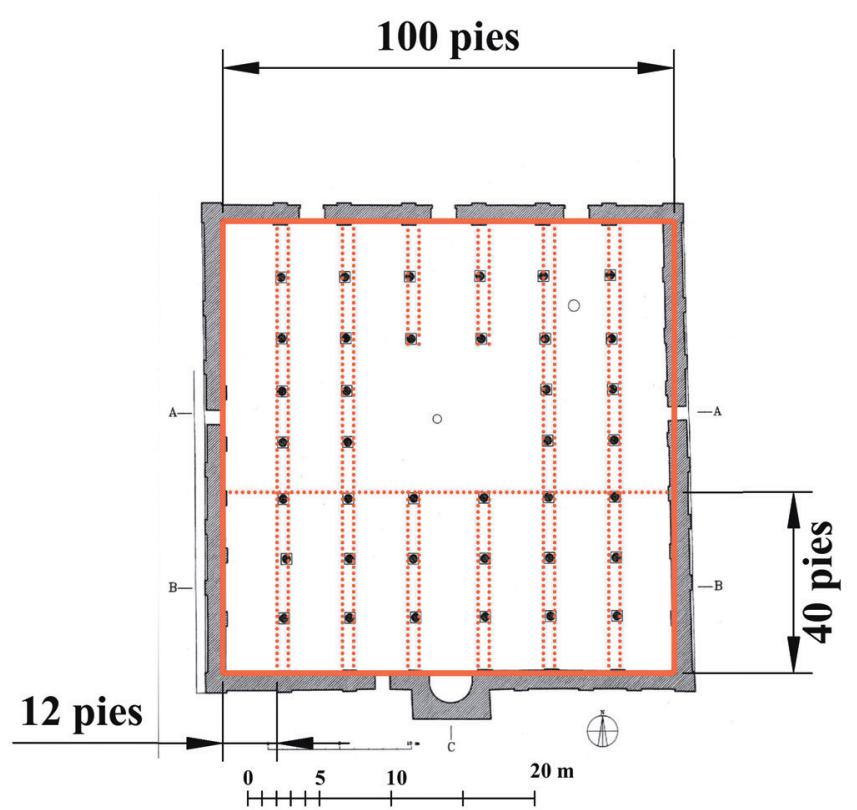

Figura 20. Análisis geométrico en pies islámicos de la mezquita de la Ciudadela de Amán sobre plano de Almagro y Jiménez (2000: fig. 9). 
posteriormente con diversas variantes, tiene como base el sistema de medida islámico. Como será habitual, el diseño parte del cálculo de la capacidad del edificio usando como planta un cuadrado de 100 pies de lado entre los paramentos interiores; a la sala de oraciones se da una longitud de 40 pies dejando el resto para el patio. Longitudinalmente el cuadrado se divide en siete naves de 12 pies cada una.

En Córdoba el arquitecto eligió la misma forma pero obtenida de otra manera. El primer recinto de la aljama cordobesa era un cuadrado de $80 \mathrm{~m}$ de lado, según se ha constatado recientemente corrigiendo la hipótesis hasta entonces vigente (Marfil 2010: 471 y ss.). Este cuadrado probablemente se trazara inscribiéndolo en una circunferencia de 360 pies de diámetro, alcanzando los 254,6 pies de lado $(80 \mathrm{~m})$. Esta será una forma habitual para trazar estructuras con planta de polígono regular como veremos abajo.

En Madinat al Zahra (Pavón 1966), la mezquita mayor, inaugurada en el año 941/329 H, se trazó siguiendo la tradición geométrica iniciada en Damasco en un modelo que encontraremos en otros lugares. El diseño del edificio se comenzó trazando el haram; su longitud interior equivale a 76 pies $(23,9 \mathrm{~m})$ y su anchura se deduce de $76 * \sqrt{2}(107,5$ pies ó $33,8 \mathrm{~m})$. Las galerías interiores se trazaron desde el lado suroccidental otorgando 20 pies a las galerías laterales y 25 pies a la central que era de mayor tamaño. El sobrante se incorpora a la primera galería anexa a la central por el lateral nordeste, que adquiere una anómala anchura de algo más de 22 pies, sumando en total los 107,5 de ancho de la sala de oraciones. El patio cuadrado se rodea de una galería por tres de sus lados con una anchura equivalente a los 20 pies de las del haram, lo que determina sus dimensiones, de manera que su anchura son 107,5 pies y su longitud es ésta menos los 20 pies de la galería sureste, 87,5 pies; el espacio libre del patio sería un cuadrado de 67,5 pies $(21,2 \mathrm{~m})$. El edificio está presidido en su fachada por un alminar cuadrado de 10 codos normales ó 15 pies $(4,7 \mathrm{~m})$.

En Sevilla la mezquita de Ibn Adabbás ${ }^{16}$ fue construida en 829-830/214 H por el cadí Ibn Adabbás en tiempos del Emir Abd al-Rahman II. A pesar de que la qibla no ha sido documentada, generalmente se ha supuesto bajo el muro sur que limita la actual iglesia del Salvador, mientras que el resto de las estructuras que limitan el edificio se han localizado durante los trabajos arqueológicos, como la división entre sahn y haram. Según esta hipótesis la mezquita se diseñó con los mismos parámetros con los que posteriormente se edificaría la de Medina Zahara: lo primero fue trazar el haram con la capacidad deseada, al que se dio una longitud interior de 90 pies o lo que es lo mismo, 60 codos mamunies o 48 codos rassasies $(28,3 \mathrm{~m})$ y una anchura de $90 * \sqrt{ } 2(127,3$ pies ó $40 \mathrm{~m}$ ). Más tarde se trazó el sahn con una longitud interior de 100 pies $(31,4 \mathrm{~m})$ con la anchura determinada por la sala de oraciones. La fachada aparece presidida

\footnotetext{
16 Sobre la primera aljama sevillana se puede consultar el trabajo de Valor (Valor 1993) y los resultados de la reciente restauración del edificio (Mendoza 2008).
}

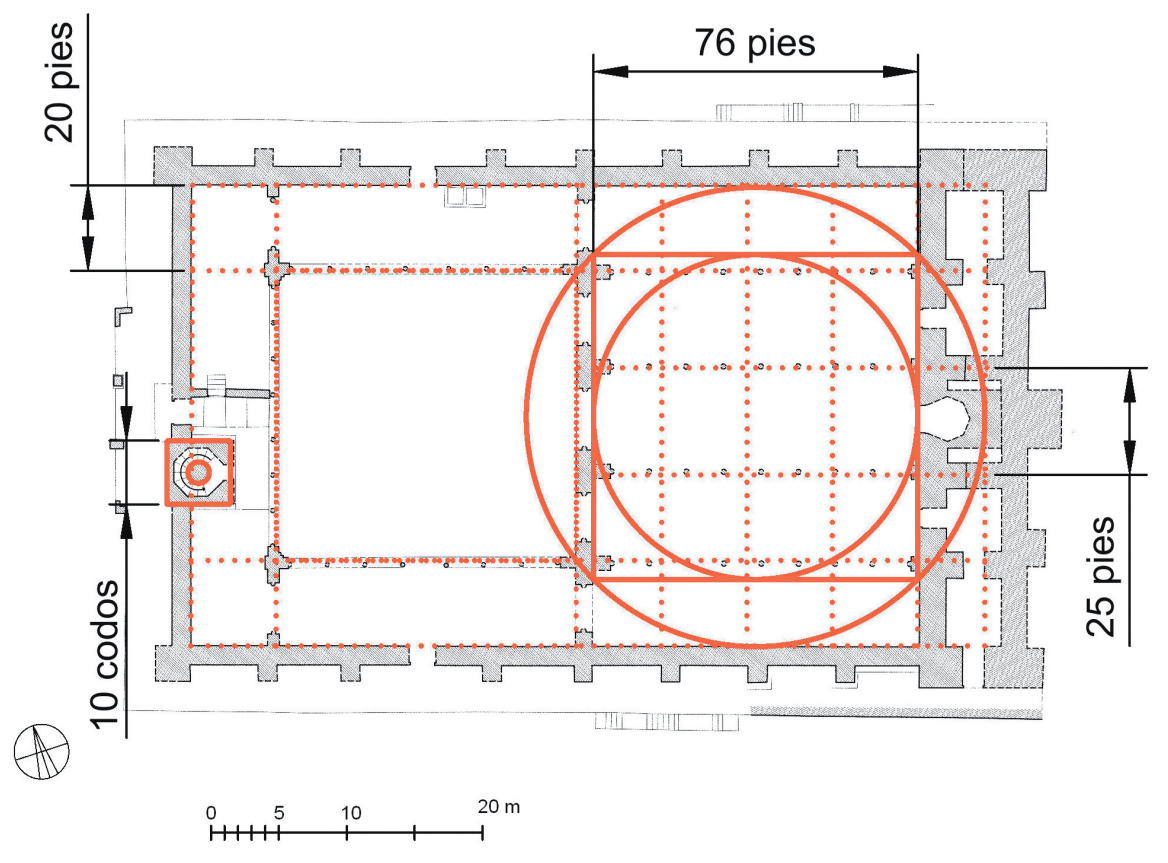

Figura 21. Análisis geométrico en pies islámicos de la mezquita de Madinat alZahra sobre plano de Almagro (2012: fig. 19). 
por un alminar de planta cuadrada de 10 codos rassasies de lado $(5,9 \mathrm{~m})$. Las galerías quedaron conformadas por la diferencia entre la longitud del patio y su anchura, es decir, 127,3 pies - 100 pies nos da los cerca de 14 pies para las galerías del patio. El haram repite estas medidas de manera que la galería central, el espacio libre entre los pilares, tenía 15 pies ó 10 codos normales, mientras que el resto de las galerías, incluido el ancho del pilar de una arcada, estarían muy próximas a los 14 pies (13,7 pies).

En 1172 bajo Yusuf I se comienza la construcción de la mezquita aljama almohade ${ }^{17}$. Este edificio repite el esquema general de la precedente aljama, la mezquita de Ibn Adabbás, tanto en lo que se refiere a su orientación como a su geometría distanciándose de los ejemplos almohades africanos ${ }^{18}$. A la nueva mezquita se la dotó de una capacidad muy superior a la de su predecesora, de manera que la longitud del haram quedó en 250 pies $(78,6 \mathrm{~m})$, establecida en el eje de los muros que la conforman, mientras que su anchura quedó determinada aplicando una razón $\sqrt{ } 2$ a la

\footnotetext{
17 Las dimensiones reales de la mezquita, su proceso constructivo y planta general se han podido confirmar gracias a los continuos trabajos arqueológicos realizados en el edificio (Jiménez 2002). Las intervenciones sobre el muro de la qibla (Tabales y Jiménez 2002) o la propia Giralda (Tabales, Huarte, García y Romo 2002).

18 La planta general del edificio no sigue los modelos coetáneos africanos, más próxima a su precedente sevillano; lo mismo podemos decir de la orientación, que conserva la extraordinaria disposición al sur como su antecesora, alejándose de los $157^{\circ}$ que marca la qibla de Tinmal y que será seguida por otros edificios almohades incluida la mezquita de Cuatrovitas en Bollullos de la Mitación (Sevilla).
}

longitud, lo que da como resultado 353,6 pies (111,1 m). El sahn tiene una longitud de la mitad de la anchura de la mezquita, es decir 55,5 m, o lo que es lo mismo, es una forma rectangular cuya anchura es dos veces su longitud, formando dos cuadrados inscritos en sendas circunferencias con un diámetro de 250 pies, igual que la longitud del haram. El alminar, la Giralda, se situó en la unión entre el sahn y el haram en el costado de levante de la mezquita y su planta es un cuadrado de lado equivalente a la décima parte de la longitud total de la mezquita $13,4 \mathrm{~m}$. La altura total del alminar islámico sería cinco veces el lado $(67 \mathrm{~m})$ pudiendo alcanzar los 150 codos mamunies $(70,71 \mathrm{~m})$. El espacio interior del haram en sentido E-O, 346,5 pies, se dividió en diecisiete naves de 20 pies de anchura cada una, exceptuando la nave central que asumió los 26,5 pies restantes. En dirección a la qibla, el interior de la sala de oraciones tenía 245,7 pies que se distribuyeron en trece arcadas (Jiménez 2007: fig. 6). Esta misma distribución determina la del sahn.

La Gran Mezquita de Tinmal erigida en 1153/547 H bajo el gobernante almohade Abd al-Mu'min en honor del mahdi Ibn Tumart, refleja algunas características que influirán en el diseño de las mezquitas almohades, entre las que destaca su orientación, y ejecutada con el mismo sistema de medida que venimos analizando. Ya se ha publicado un análisis metrológico del edificio (Wisshak 1989) en el que se establecía un módulo de 64 $\mathrm{cm}$ ( 2 pies) mientras que la planta cuadrada del edificio

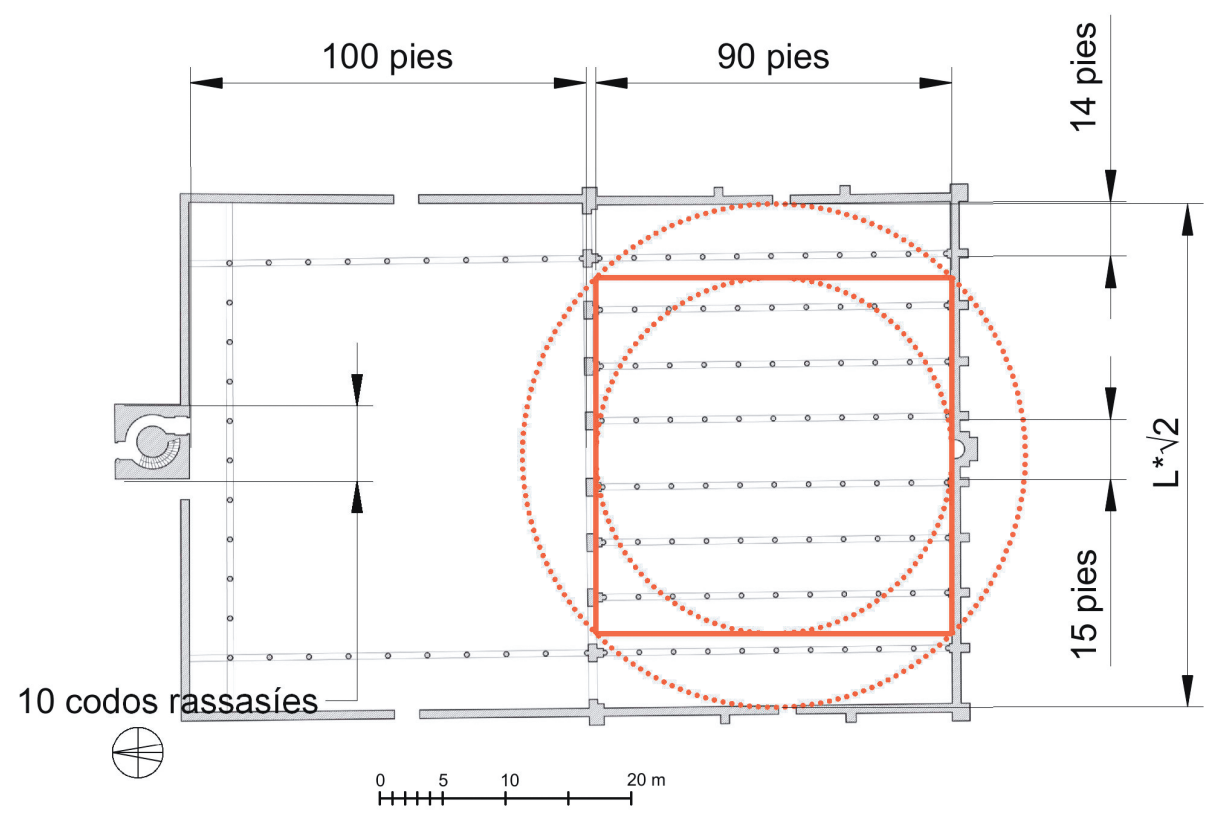

Figura 22. Análisis geométrico en pies islámicos de la mezquita aljama de Ibn Adabbás de Sevilla sobre plano de Almagro (2008, fig. 20). 


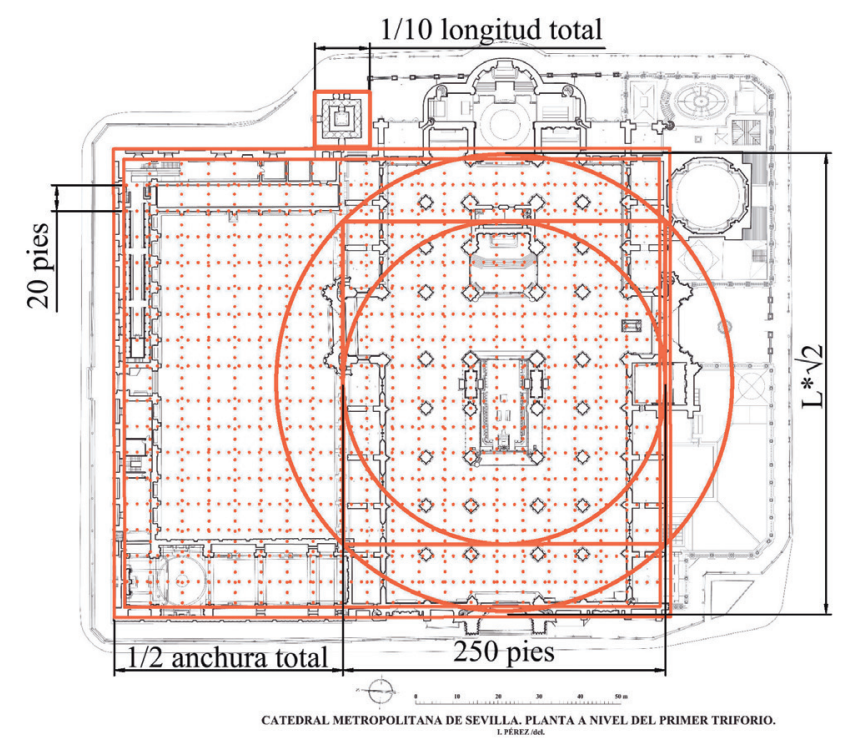

Figura 23. Análisis geométrico en pies islámicos de la gran mezquita almohade de Sevilla sobre planta actual de la catedral realizada por Almagro y Zúñiga (2007: fig. 3).

tenía una diagonal de 100 módulos (200 pies). Aunque en líneas generales los resultados muestran el uso del pie islámico como patrón de medida, la planimetría que nosotros usamos (Ewert 1973: fig. 3), nos muestra que la planta del edificio es un cuadrado de 150 pies ó 100 codos normales de lado $(47,1 \mathrm{~m})$; el haram tiene una longitud interior de 75 pies, la mitad del lado de la mezquita. El interior se distribuye en nueve galerías entre las que destaca la central, con 18 pies de ancho ó 22 pies si incluimos las dos arcadas que la conforman; las galerías perimetrales y la anexa a la qibla tienen una luz de 15 pies ó 10 codos normales, mientras que las restantes adquieren esta dimensión pero incorporando el ancho de la arcada. El patio tiene unas medidas de 75 pies de ancho por 50 de largo. El porqué de estas dimensiones y de la propia orientación del edificio posiblemente esté en el deseo de su diseñador de seguir estrictamente los pasos del Profeta; la mezquita adquiere la misma forma y dimensiones de la casa de Mahoma en Medina, un cuadrado de 100 codos de lado, incluso el número de naves puede ser un recuerdo de los nueve cobertizos que componían su casa (Creswell 1989: 4-5). No obstante, la orientación difiere de la de este edificio y probablemente se rija siguiendo el proceso por el cual se cambió el sentido de la oración cuando Mahoma volvió su rostro a la Meca dando la espalda a Jerusalén. Esa línea virtual que une Jerusalén con la Meca tiene una orientación de $157^{\circ}$, la que adopta la qibla almohade de Tinmal y de otras muchas que le suceden.

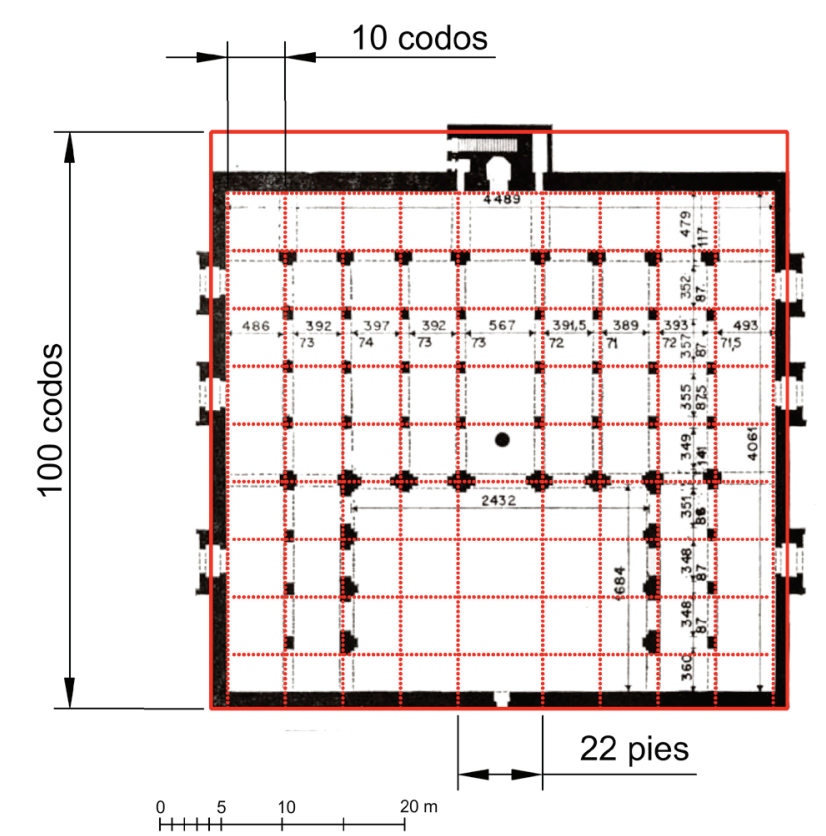

Figura 24. Análisis geométrico de la Gran Mezquita de Tinmal en codos y pies islámicos sobre plano de Ewert (1973: fig. 3).

Analizando una serie de edificios religiosos relevantes del Islam hemos podido documentar el uso común de un mismo sistema de medida independientemente del lugar y de la época, lo que sirve de sostén para mantener la hipótesis de un mismo sistema de medidas lineales en todo el Islam; además, la mayor parte de ellos surgen de formas geométricas comunes, de un lado el rectángulo con razón $\sqrt{ } 2$ entre longitud y anchura posiblemente originado en el modelo de la Gran Mezquita de Damasco y por otro, el cuadrado que recuerda la forma de la casa de Mahoma en Medina.

\section{Análisis metrológico en los Reales Alcázares de Sevilla}

Al igual que lo observado en las mezquitas, los alcázares, edificios palatinos protegidos por un recinto amurallado, van a seguir unas formas que deben su diseño a los primeros recintos omeyas. En el Real Alcázar de Sevilla vamos a encontrar soluciones que se repetirán más o menos transformadas a lo largo del territorio islámico.

Qsar al-Mshatta fue construido por el califa omeya Walid II poco antes de su muerte en 744/126 H. Se trata de un recinto amurallado cuadrado de 240 codos rassasíes de lado o lo que es lo mismo 300 codos mamunies ó 450 pies, que protegen un palacio originado en torno a un gran patio cuadrado de 100 codos rassasíes de lado, con el cuerpo edilicio principal ubicado al norte de 70 codos rassasies de anchura. 


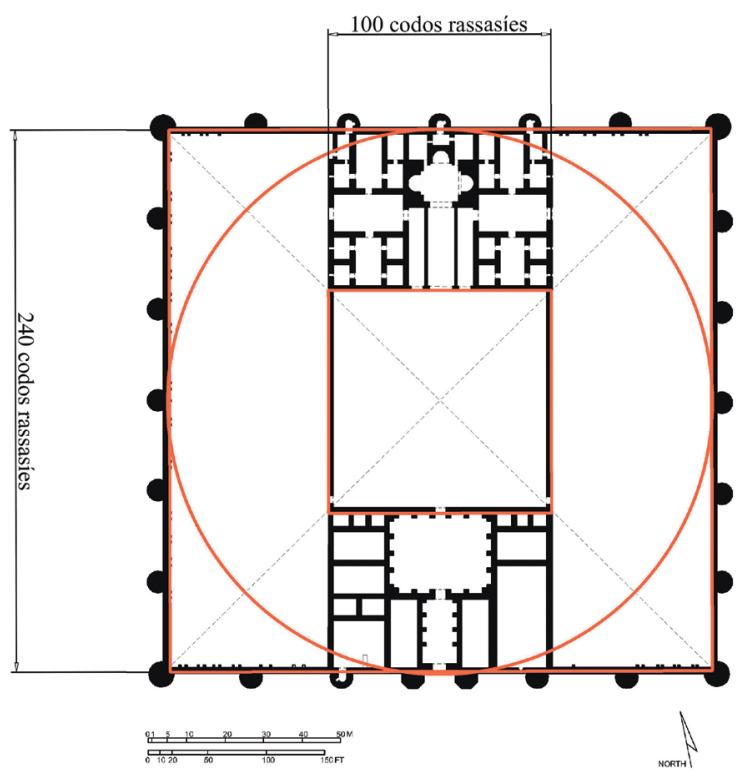

Figura 25. Análisis metrológico de Qsar al-Mshatta en codos rassasíes sobre plano de Nasser Rabat (Archnet.org).

En España el elemento más próximo a la forma del alcázar sevillano quizás sea la gran alcazaba de Mérida que tiene forma de cuadrado inscrito en una circunferencia de 600 pies islámicos de diámetro. Un palacio arropa el gran recinto amurallado de la Aljafería que tiene una forma irregular próxima al cuadrado de 240 pies de lado en su costado occidental.

El Alcázar de Sevilla es uno de los lugares donde mejor podemos observar la diversidad de sistemas de medida que ofrecen un contraste nítido entre las distintas etapas culturales y cronológicas a partir del diseño de los edificios y estructuras, como ya hemos podido observar también en el análisis mensiocronológico de las fábricas de ladrillo.

El conjunto edilicio de los Reales Alcázares de Sevi1la formado a lo largo de casi mil años ininterrumpidos de construcciones, demoliciones, reformas y adiciones, presenta una complejidad extrema a la hora de comprender su proceso evolutivo, de desvelar los pasos que han dado lugar a lo que hoy vemos. Desde distintas disciplinas han sido muchas las propuestas sobre el origen y evolución del conjunto ${ }^{19}$. El proyecto continuado de investigación arqueológica en el Real Alcázar ha aportado valiosa información que ayuda a solventar muchas de las incógnitas previas que, a su vez, induce a nuevas cuestiones que habrá que resolver en el futuro. En primer lugar, se ha establecido una fecha para la creación del primer edificio

\footnotetext{
19 Véase (Tubino 1999; Manzano 1999; Guerrero 1974; Valor 1991).
}

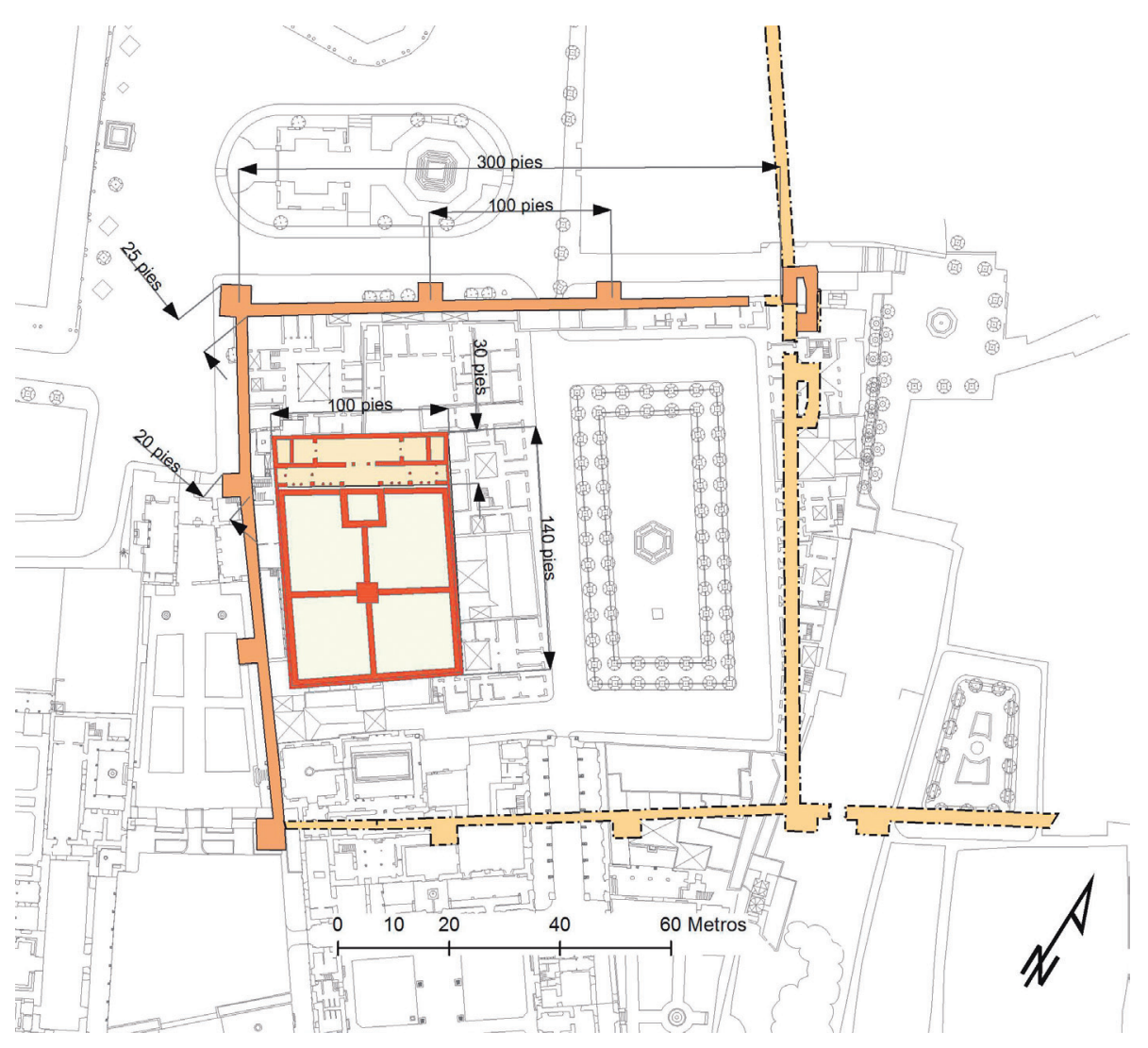

Figura 26. Análisis metrológico del Recinto I del Real Alcázar de Sevilla en unidades islámicas, según la interpretación de Tabales y Vargas 2014. 
y se ha esbozado un proceso evolutivo que da coherencia al conjunto.

El Alcázar de Sevilla tiene su origen en un núcleo primario, construido a finales del siglo XI, formado por un recinto amurallado de 300 pies de lado con torres equidistantes cada 100 pies; la muralla tiene una anchura de 6 pies $(1,89$ unidades) mientras que las torres se diseñaron inscribiendo un cuadrado en una circunferencia de 25 pies de diámetro para las de las esquinas $(5,55 \mathrm{~m}$ de lado) y de 20 pies para las torres de flanqueo (torres de 4,4 $\mathrm{m}$ de lado). Esta manera de trazar es común a las torres poligonales del lienzo que avanza hasta el río que incluye la torre hexagonal de Santo Tomás, la octogonal de la Plata y la dodecágona del Oro. La torre de Santo Tomás es un hexágono inscrito en una circunferencia de 15 pies de diámetro o 10 codos mamuníes; la Torre de la Plata se trazó circunscribiendo un octógono en un círculo de 30 pies de diámetro o 20 codos mamunies, compartiendo diseño con la Torre del Oro cuya planta parte de la circunscripción de un dodecágono en una circunferencia de 50 pies de diámetro, de lo que parece inferirse que ambas pudieron ser diseñadas al mismo tiempo (Valor 2008: 72-83). El primer recinto del Alcázar defendía un edificio palaciego de planta rectangular de 100 pies de ancho y una longitud documentada de unos 140 pies. El cuerpo del palacio tenía una anchura de 30 pies entre la crujía principal y la galería que se le anteponía ${ }^{20}$.

Posteriormente, este recinto se amplía hacia el sur para dar acogida a un segundo palacio, mucho mayor

\footnotetext{
20 Estos son los resultados preliminares de una reciente intervención arqueológica en las casas 7-8 del Patio de Banderas que han permitido definir la estructura general del palacio (Tabales y Vargas 2014).
}

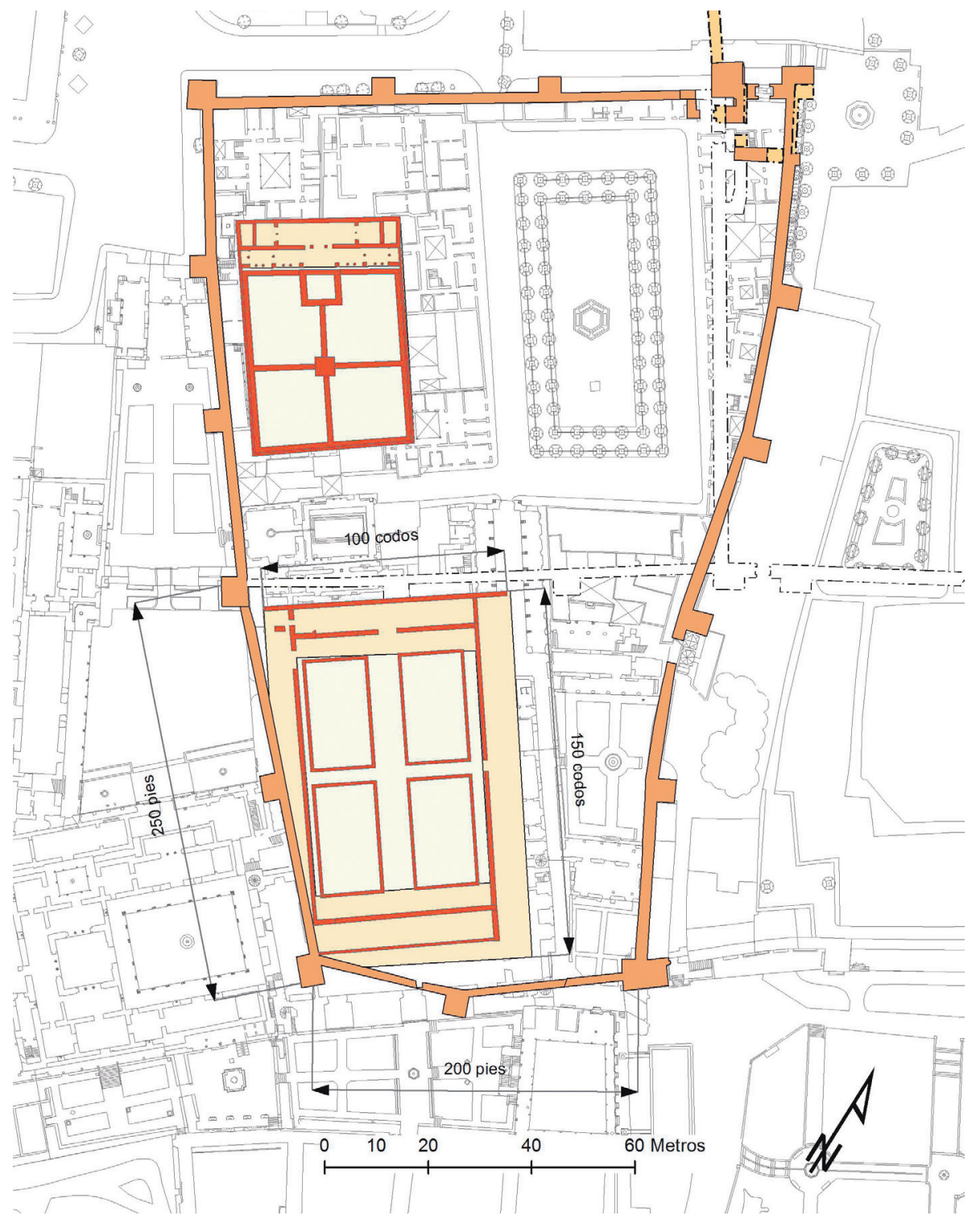

Figura 27. Análisis metrológico del Recinto II del Real Alcázar de Sevilla en unidades islámicas sobre interpretación de Tabales y Vargas 2014. 
que el primero (Tabales 2002b). Esta ampliación es mensurable en unidades enteras del sistema islámico; para acoger el nuevo edificio, la ampliación de la cerca adquiere una forma trapezoidal con el lado norte de los 300 pies del recinto primero hasta los 200 pies del lado sur, mientras que los lados oriental y occidental medirían 250 pies islámicos. El palacio al que protegía el recinto amurallado estaba construido en torno al inmenso Patio del Crucero que hoy antecede al palacio gótico. Las restituciones realizadas sobre dicho edificio (Almagro 1999; Tabales 2001), a pesar de no haber sido objeto de una profunda investigación arqueológica nos hacen percibir que este palacio era mucho mayor que el del primer recinto; y aunque la anchura del cuerpo principal mantuviese los 30 pies, su anchura pudo alcanzar los 150 pies ó 100 codos y su longitud hasta los 150 codos, escalando una vez y media la planta de su antecesor.

Más tarde, un tercer recinto alojaría un nuevo palacio de dimensiones muy similares a las del recinto I. El palacio ubicado en la Casa de la Contratación fue descubierto, excavado y restaurado por Rafael Manzano en 1973; documentó dos grandes fases constructivas, una que dató en época taifa y una segunda que transformaba de manera radical la morfología del patio en período almohade (Vigil-Escalera 1999). Durante la intervención en el edificio se documentó el patio y gran parte de las estructuras del ala norte del palacio, mientras que al sur sólo se documentó el arranque de uno de los pilares, por lo que su restitución se realizó considerando el edificio simétrico, dado que las obras durante la Edad Moderna no preservaron ninguna de las estructuras precedentes como sí ocurrió en el lado norte. El palacio, según esta configuración, tendría una longitud de 100 pies y una anchura de 30 pies islámicos, exactamente las mismas dimensiones que el palacio del recinto I, aunque difiere en la longitud total que, en este caso, llega a los 156 pies, aunque mostramos ciertas dudas sobre la fidelidad de esta restitución.

Los espacios libres entre estos tres recintos se fueron ocupando de construcciones palaciegas de menor rango y tamaño que llegaron a colmatar todo el ámbito en una abigarrada trama urbana. Entre estos palacios destacan el Patio del Yeso y el palacio documentado durante los trabajos arqueológicos en el Patio de la Montería (Tabales 2000), con unas dimensiones similares, de planta cuadrada de 80 pies islámicos de lado, aunque el palacio del Yeso tiene uno de los lados ligeramente menor de 78 pies, tamaño que contrasta con el de los grandes palacios que presiden los tres recintos amurallados.

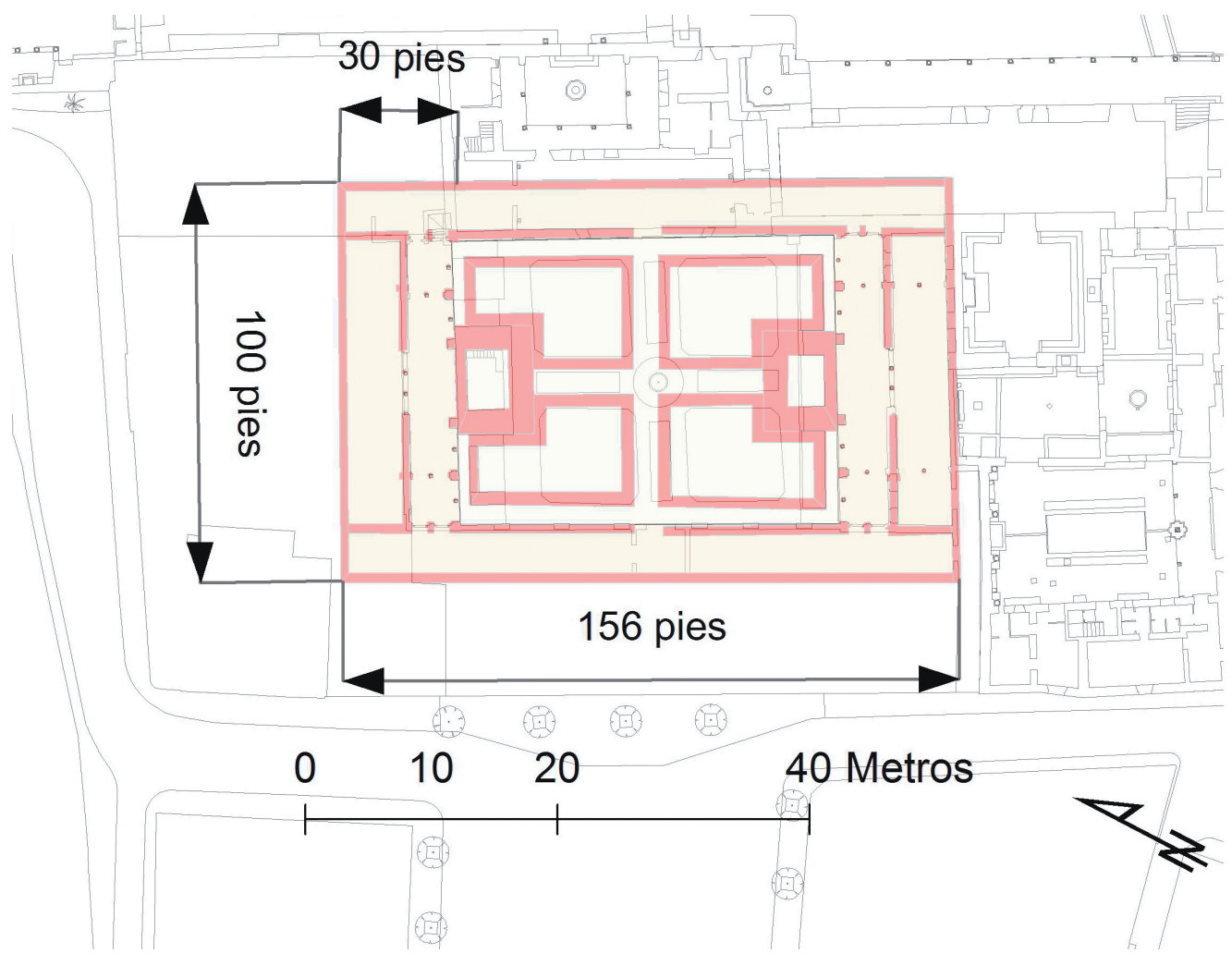

Figura 28. Análisis metrológico del palacio de la Casa de la Contratación de Sevilla en unidades islámicas. 
La conquista cristiana de Sevilla provocará una drástica transformación de los alcázares islámicos que se evidencia de una manera muy elocuente en el Palacio Gótico. El Palacio Gótico supone un cambio radical en el diseño, forma de construir, lenguaje formal, orientación, renunciando a la arquitectura orientada al sol que constituía una premisa básica en la arquitectura islámica y también por supuesto, en el sistema de medida con el que se diseñó. El bloque del palacio se articula en una rejilla de 100 pies castellanos de largo por 200 pies de ancho, con una pequeña variación en su costado occidental por su adaptación al lienzo de muralla preexistente.

No obstante, la mayor transformación vino producida por la ambiciosa intervención de Pedro I. Para ello aprovechó el espacio existente entre los recintos I-II y III, demoliendo las construcciones menores, habilitando un nuevo eje de acceso y delimitando nuevos espacios funcionales (Almagro 2013). Si bien el Palacio Gótico no ofrece dudas sobre el carácter cristiano de su concepción y erección, el Palacio de Pedro I no está tan claro para algunos investigadores. A pesar de las evidencias arqueológicas contrastadas ${ }^{21}$ todavía se sostiene que

21 Las excavaciones arqueológicas realizadas en el Patio de las Doncellas no dejan lugar a dudas sobre el proceso constructivo del nuevo palacio que arrasa las construcciones precedentes para su erección (Tabales 2005). el palacio reaprovecha un edificio precedente (Cómez 2007: 333-334), o también que fue construido con formas y sistema de medida islámicos (Rodríguez 2012: 499-520).

El análisis metrológico del edificio parece apuntar a una obra castellana desde su concepción realizada con pies castellanos. El edificio se ejecuta a partir de la línea formada por los contrafuertes occidentales del palacio Gótico y de la línea de fachada perpendicular a esta primera. El eje del patio se establece a 100 pies de la línea de fachada, otorgando a éste 80 pies de anchura desde los ejes de los muros que lo limitan; la longitud del patio es de 100 pies desde el paramento del palacio Gótico hasta el eje del muro que cierra la qubba de los Embajadores por el noreste. Las crujías que cierran el palacio en sus costados suroeste y sureste tienen 25 pies castellanos de anchura contados desde los paramentos externos de los muros. La qubba es el elemento más significativo del palacio y su diseño se realizó en unidades castellanas: su planta interior es un cuadrado inscrito en un círculo de 50 pies de diámetro que implica un lado de 35,35 pies o 40 pies de eje a eje de los muros que la conforman. Además, estas medidas se repiten en las otras dos salas cuadradas del Alcázar: tanto la sala de la Justicia como el cuarto del Almirante son cuadrados de 40 pies de lado entre los ejes de sus muros.

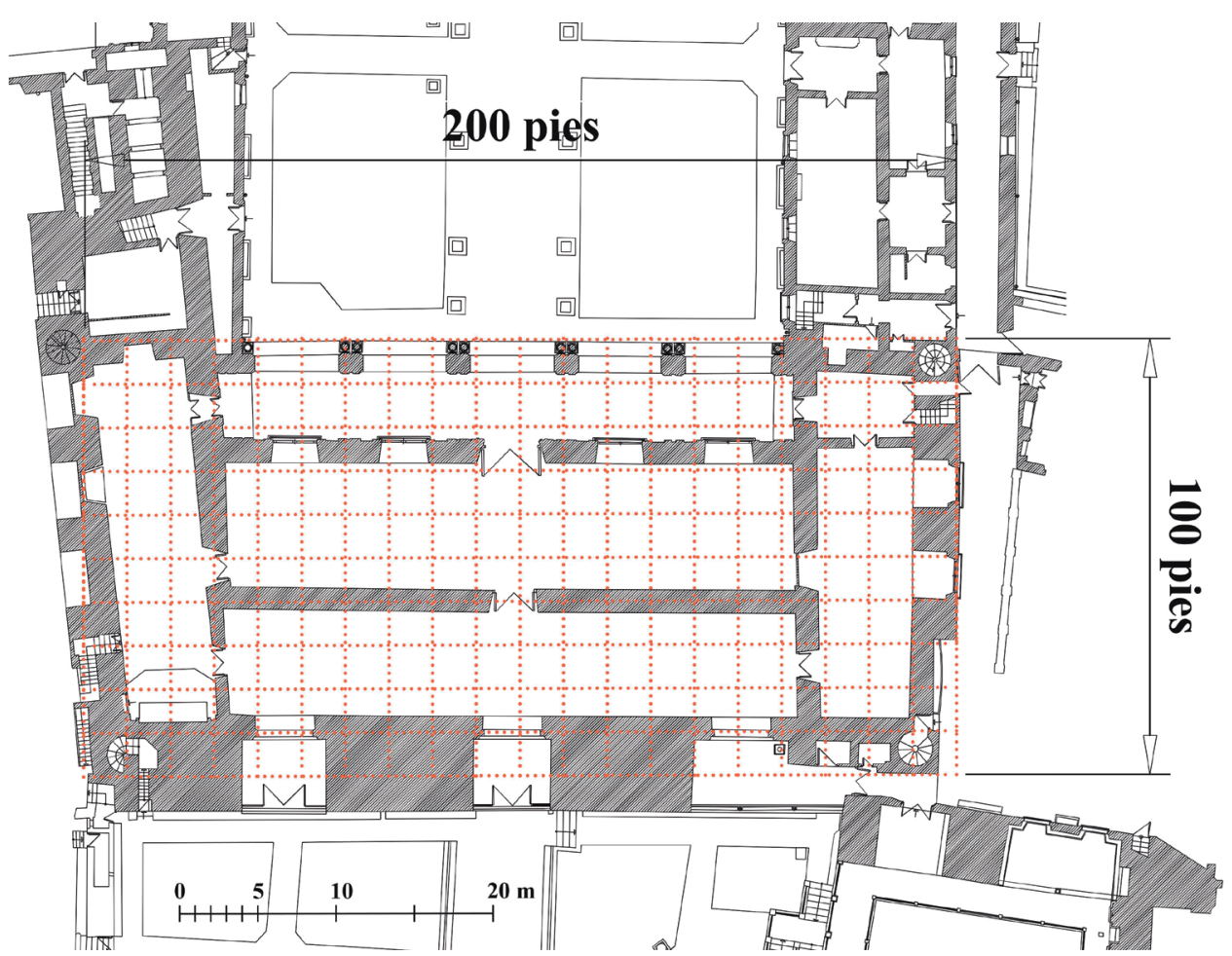

Figura 29. Análisis metrológico del Palacio Gótico del Real Alcázar de Sevilla en unidades de medidas castellanas sobre plano de Almagro (2003: fig. 19). 
De este análisis se pueden extraer las siguientes conclusiones:

- El palacio de Pedro I es un edificio de nueva planta que se adapta a un espacio previamente urbanizado, en el que, tras la demolición exhaustiva del área destinada al nuevo palacio, se construye sin aprovechar ninguna estructura previa, como ya se había demostrado a partir de los trabajos arqueológicos realizados.

- El palacio fue mandado construir por un rey castellano empleando el sistema de medida castellano. Aunque en su construcción participasen trabajadores y artesanos islámicos, el diseño es castellano.

- El hecho de que las tres qibab sean de dimensiones idénticas, basadas en un mismo diseño, parece indicar que son parte de un mismo proyecto arquitectónico como se ha apuntado recientemente (Almagro 2013).

\section{CONCLUSIONES}

Las características métricas de una pieza, un aparejo, estructura o edificio son tan valiosas para establecer una tabla tipológica como las características formales y materiales; la analogía, con base exclusiva en características observables a simple vista: forma, color, textura, etc. son, muchas veces, insuficientes para individualizar elementos aparentemente idénticos; debemos acudir, entonces, a su caracterización fisicoquímica o también a sus medidas.

Llevamos años ensayando y depurando una serie de técnicas que nos permitan de manera fiable esta caracterización, desde los materiales de construcción y la forma de aparejar, hasta el estudio de los edificios de distintas épocas a partir de su geometría y sistema de medida bajo el que fue creado. Tanto es así, que hoy

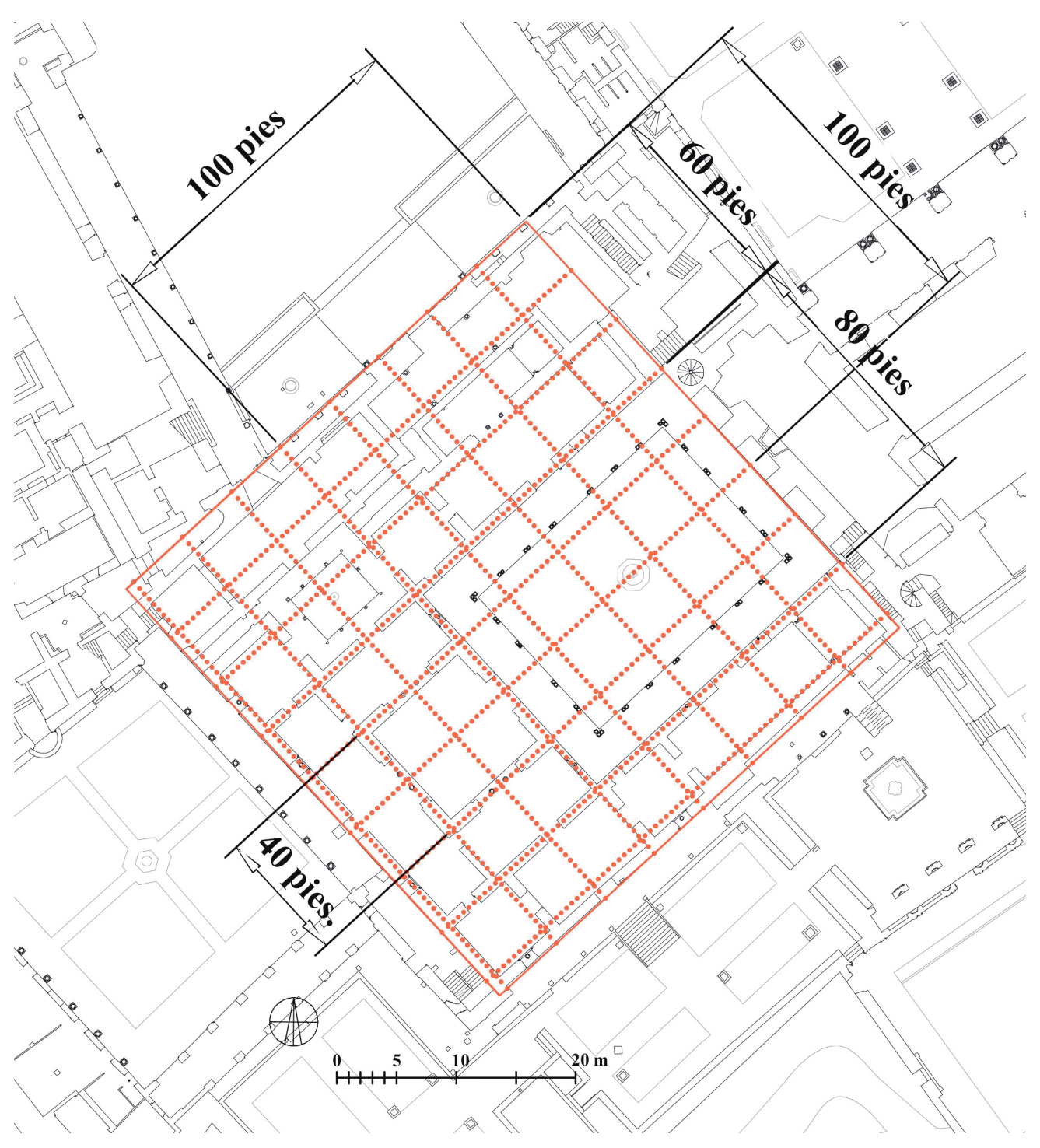

Figura 30. Análisis geométrico del palacio de Pedro I en el Real Alcázar de Sevilla en unidades de medidas castellanas. 
creemos estar en condiciones de adscribir cronológica y culturalmente toda una serie de fábricas de ladrillo a partir de sus medidas. El análisis estadístico de fábricas latericias nos ha dado buenos resultados tanto en Sevilla como en Carmona, lugares en los que hemos establecido una tabla básica de referencia de formatos de ladrillos.

Los aparejos que dan forma a las estructuras son el resultado de la combinación de diferentes elementos en una proporción precisa que nos sirven para caracterizar metrológicamente diferentes estructuras para establecer una tabla tipológica con base en analogías metrológicas y formales.

Probablemente, los resultados más sorprendentes los obtenemos en el análisis metrológico y geométrico de los edificios. En el camino inverso de la ruina al plano, la deducción de la idea que inspiró al arquitecto para diseñar un edificio a partir de sus conocimientos geométricos y matemáticos desde un sistema de medida impuesto por el estado al que sirve, arroja mucha luz sobre el estudio de la arquitectura antigua. El análisis de las mezquitas, aunque se trate de una muestra preliminar, sugiere de un lado el uso generalizado del sistema de medida islámico en todo el territorio bajo su dominio, y de otro la formalización de una serie de formatos geométricos que se repetirán en un vasto territorio durante un largo período cronológico.

La hipótesis central del empleo generalizado para todo el territorio islámico de un único sistema lineal se sustenta en su aplicabilidad a piezas de pequeño formato, a estructuras arquitectónicas y al análisis geométrico de grandes edificios. En estos últimos las diferencias entre el modelo teórico sobre la planimetría no superan de manera general el 1\% y sólo en algunas ocasiones, las rebasa ligeramente sin alejarse de este valor. Además, el error no se incrementa con el aumento de la distancia desde el punto inicial de la trama sino que se mantiene constante, hecho que no ocurre aplicando otros valores. También se ha podido apoyar la aplicación del sistema de medida castellano en las obras realizadas tras la conquista cristiana, tanto a sus edificios como a sus materiales de construcción. Todo nos lleva a reforzar la idea de que los sistemas de medida eran inalterables en los territorios de un estado, dadas las imprevisibles consecuencias que en su economía tendría un sistema de pesas y medidas cambiante. $\mathrm{Y}$ si este hecho es asumido para el período romano y para el momento actual (donde un sistema variable de pesas y medidas sería impensable) ¿por qué no se aplica a la Edad Media?

El uso de estas técnicas en el Real Alcázar de Sevilla ha ayudado a contrastar hechos que siguen en controversia; en este aspecto, destaca que el palacio de Pedro I fue una construcción de nueva planta, que no reutilizó ninguna estructura anterior, aunque formalmente imitara elementos culturales islámicos califales incorporados, eso sí, a un edificio diseñado a partir de presupuestos ideológicos cristianos bajo un sistema de medida castellano.

Sin duda, la Arqueología tiene herramientas para resolver las incógnitas científicas que el Alcázar nos presente, en un proceso largo, paciente y continuo que nos ayude a desvelar las nuevas preguntas que a diario se nos presentan y ante estos retos, hay que tomar medidas.

\section{Referencia administrativa}

Este trabajo se realiza dentro del Proyecto de Investigación de Excelencia Análisis Estratigráfico y Cronotipológico de los Recintos Fortificados del Alcázar de Sevilla. Procedimientos, Sistemas y Aplicaciones desde su Vertiente Constructiva. (P12-TEP-1843).

\section{BIBLIOGRAFÍA}

Adam, J. P. 2002. La construcción romana: materiales y técnicas. Editorial de los Oficios, León.

Almagro Gorbea, A. 1999: "El Patio del Crucero de los Reales Alcázares de Sevilla". Al-qantara: Revista de estudios árabes, $X X$.

Almagro Gorbea, A. 2003: Planimetría del Alcázar de Sevilla. Granada.

Almagro Gorbea, A. 2004: Levantamiento arquitectónico. Editorial Universidad de Granada. Granada.

Almagro Gorbea, A. 2008: Planimetría de la Iglesia Colegial del Divino Salvador de Sevilla. Consejo Superior de Investigaciones Científicas, CSIC. Granada.

Almagro Gorbea, A. 2012: Planimetría de Madinat al-Zahra'. Escuela de Estudios Árabes CSIC. Granada.

Almagro Gorbea, A. 2013: "Los palacios de Pedro I. La arquitectura al servicio del poder". Anales de historia del arte 2, pp. 25-49.

Almagro Gorbea, A. y Jiménez Castillo, P. 2000: "The Umayyad Mosque of the Citadel of Amman". Annual of the Department of Antiquities of Jordan, $X L I V$, pp. 459-475.

Almagro Gorbea, A. y Zúñiga Urbano, J. I. 2007: Atlas arquitectónico de la Catedral de Sevilla. CSIC - Escuela de Estudios Árabes (EEA) Cabildo de la Santa, Metropolitana y Patriarcal Iglesia Catedral de Sevilla. Sevilla-Granada.

Altarriba, M., Guillén, C., Rojo, N., Martí, J. y Guzmán, R. 2001: “Una propuesta de curva mensiocronológica latericia para la ciudad de Valencia". Actas: V Congreso de Arqueología Medieval Española, Valladolid, 22 a 27 de marzo de 1999, pp. 235-254.

Arenas Rodríguez, P., Carrasco Gómez, I., Conlin Hayes, E., Jiménez Hernández, A. y Lafuente Ibáñez, P. 2004: "El palacio de Hernando Colón: arqueología de la arquitectura en el patio de San Laureano (Sevilla)". Romula, 3, pp. 285-310.

Bridger, C. J. 1984: "The «Pes Monetalis» and the «Pes Drusianus» in Xanten". Britannia, 15, pp. 85-98.

Caballero Zoreda, L. y Utrero Agudo, M. de los A. 2005: "Una aproximación a las técnicas constructivas de la Alta Edad Media en la Península Ibérica. Entre visigodos y omeyas". Arqueología de la Arquitectura, 4, pp. 169-192.

Cardarelli, F. 2003: Encyclopaedia of Scientific Units, Weights and Measures: Their Si Equivalences and Origins. Springer - Verlag. 
Carrasco Gómez, I. y Jiménez Hernández, A. 2008: “Arqueología de la Arquitectura en el Convento de Concepción de Carmona (Sevilla)". Carel, 6, pp. 2499-2581.

Cómez Ramos, R. 2007: "Historia del arte y arqueología en los nuevos hallazgos del Alcázar de Sevilla”. Archivo hispalense: Revista histórica, literaria y artística, 90, pp. 313-334.

Creswell, S. K. A. C. 1989: A short account of Early Muslim architecture. (J. Wilson Adams, Ed.). Scholars Press.

Duncan-Jones, R. P. 1980: "Length-Units in Roman Town Planning: The Pes Monetalis and the Pes Drusianus". Britannia, 11, pp. 127-133.

Eguaras Ibáñez, J. 1988: Ibn Luyūn, tratado de agricultura. Publicaciones del Patronato de la Alhambra. Granada.

Ewert, C. 1973: "La mezquita de Mértola (Portugal)". Cuadernos de la Alhambra, 9, pp. 3-35.

Flood, F. B. 2001: The Great Mosque of Damascus: Studies on the Makings of an Ummayyad Visual Culture. BRILL.

Guerrero Lovillo, J. 1974: Al-Qasr al-Mubarak. El Alcázar de la bendición. Sevilla.

Graciani García, A. y Tabales Rodríguez, M. Á. 2008. "El tapial en el área sevillana. Avance cronotipológico estructural." Arqueología de La Arquitectura, 5, pp. 135-58.

Hernández Jiménez, F. 1961: "El codo en la historiografía árabe de la Mezquita Mayor de Córdoba. Contribución al estudio del monumento". Al-Mulk, 2, pp. 5-52.

Hernández Jiménez, F. 1975: El alminar de Abd al-Rahman III en la Mezquita Mayor de Córdoba: génesis y repercusiones. Patronato de la Alhambra. Granada.

Hernández Vera, J. A. 2004: "La mezquita aljama de Zaragoza a la luz de la información arqueológica". Ilu. Revista de ciencias de las religiones. Anejos 10, pp. 65-92.

Hultsch, F. O. 1882: Griechische und römische metrologie. Weidmann. Berlin.

Jiménez Hernández, A. 2002: "El Puente sobre el Tagarete en el paso de Miraflores. :Parque de Miraflores, Sevilla”. Anuario Arqueológico de Andalucía 1999, pp. 909-922. Sevilla.

Jiménez Martín, A. (Ed.). 2002: Magna Hispalensis (I) Recuperación de la Aljama Almohade. Aula Hernán Ruiz. Cabildo Metropolitano. Granada.

Jiménez Martín, A. 2007. "Notas Sobre La Mezquita Mayor de La Sevilla Almohade." Artigrama: Revista Del Departamento de Historia Del Arte de La Universidad de Zaragoza, no. 22, pp. 131-54.

Lara García, M., López Gallardo, R., Jiménez Hernández, A. y Romero Moragas, C. 1998: "La Hacienda de Miraflores y la Huerta de la Albarrana: dos antiguas propiedades agrícolas dentro del Parque Miraflores de Sevilla". En M. Valor Piechotta y C. Romero Moragas (Eds.), Sevilla Extramuros. La huella de la Historia en el sector oriental de la ciudad, pp. 149-194. Salamanca.

Lévi-Provençal, E. y García Gómez, E. 1998. Sevilla a comienzos del siglo XII: el tratado de Ibn-'Abdun. Colegio Oficial de Aparejadores y Arquitectos Técnicos. Sevilla.

Mannoni, T. y Milanese, M. 1988. "Mensiocronologia.” En R. Francovich y R. Parenti Archeologia E Restauro Dei Monumenti. I Ciclo Di Lezioni Sulla Ricerca Applicata in Archeologia (Certosa Di Pontignano 1987), pp. 383-402. Firenze: All'Insegna del Giglio.

Manzano Martos, R. 1999: "Los palacios". Sevilla almohade, 63-75. SevillaRabat.

Marfil Ruiz, P. F. 2010: Las puertas de la Mezquita de Córdoba durante el Emirato Omeya (Tesis Doctoral).Universidad de Córdoba. Córdoba.

Mauss, C. 1888: "Note sur la méthode employée pour tracer le plan de la mosquée d'Omar et la Rotonde du Saint-Sépulchre à Jérusalem." Revue Archéologique, Troisième Série, 12 (July), pp. 1-31.

Mendoza, F. 2008: La iglesia del Salvador de Sevilla: biografia de una colegiata. Editorial Tébar Flores, S.L. Madrid.

Navas Cámara, L., Martínez Aranaz, B., Cabañero Subiza, B. y Lasa Gracia, C. 1995: "La excavación de urgencia de la Plaza Vieja (Tudela-1993): La necrópolis cristiana y nuevos datos sobre la Mezquita Aljama”. Trabajos de arqueología navarra 12, pp. 91-174.
Oliva Muñoz, P. y Tabales Rodríguez, M. Á. 2011. "De palacio a monasterio: génesis y transformación del Real Monasterio de Santa Clara de Sevilla." Arqueología de La Arquitectura, 8, pp. 141-62.

Pavón Maldonado, B. 1966: "Memoria de la excavación de la mezquita de Medinat al Zahra”. Excavaciones Arqueológicas en España 50. Dirección General de Bellas Artes. Madrid.

Quirós Castillo, J. A. 1996: "Indicadores cronológicos de ámbito local: cronotipología y mensiocronología". Arqueología de la Arquitectura. El método arqueológico aplicado al proceso de estudio y de intervención en edificios históricos (Burgos, 1996), pp. 179-186. Valladolid.

Rodríguez Moreno, C. 2012: El palacio de Pedro I en los Reales Alcázares de Sevilla estudio y análisis. Universidad de Granada, Granada.

Rottländer, R. C. A. 1979. Antike Längenmaße, Vieweg, Wiesbaden.

Ruiz de la Rosa, J. A. 1986: Control formal en arquitectura: aproximación a la Edad Antigua y Media. Universidad de Sevilla. Sevilla.

Ruiz de la Rosa, J. A. 1987: "Geometría fabrorum: o la antítesis de las teorías sofisticadas". Boletín académico 7, pp. 52-59.

Tabales Rodríguez, M. Á. 2000: "Investigaciones Arqueológicas en el Real Alcázar de Sevilla. Notas Sobre Evolución Constructiva y Espacial”. Apuntes del Alcázar de Sevilla, 1, pp. 12-45.

Tabales Rodríguez, M. Á. 2001: "La transformación palatina del Alcázar de Sevilla, 914-1366". Anales de arqueología cordobesa 12, pp. 195-213.

Tabales Rodríguez, M. Á 2002a: Sistemas de análisis arqueológico de edificios históricos. Universidad de Sevilla. Sevilla.

Tabales Rodríguez, M. Á. 2002b: "El Alcázar Islámico de Sevilla”. Castillos de España: publicación de la Asociación Española de Amigos de los Castillos 125, pp. 39-46.

Tabales Rodríguez, M. Á. 2005: "El Patio de las Doncellas del Palacio de Pedro I de Castilla. Génesis y Transformación”. Apuntes del Real Alcázar de Sevilla, 6, pp. 7-43.

Tabales Rodríguez, M. Á 2010: El Alcázar de Sevilla : reflexiones sobre su origen y transformación durante la Edad Media : memoria de investigación Arqueológica 2000-2005. Junta de Andalucía Consejería de Cultura y R.A. Sevilla.

Tabales Rodríguez, M. Á. 2013. "Origen Y Alcázar Islámico.” Apuntes Del Real Alcázar de Sevilla 14, pp. 94-117.

Tabales Rodríguez, M. Á., Huarte, R., García, E. y Romo, A. S. 2002: "Estudio Arqueológico del Basamento Pétreo y Cimientos de la Giralda”. En A. Jiménez Martín (Ed.), Magna Hispalensis (I). Recuperación de la Aljama Almohade, pp. 169-228, Aula Hernán Ruiz, Cabildo Metropolitano, Granada.

Tabales Rodríguez, M. Á. y Jiménez Sancho, Á. 2002: "La Cilla de la Catedral y el Sector Meridional de la Mezquita Aljama de Sevilla". En A. Jiménez Martín (Ed.), Magna Hispalensis ( I ). Recuperación de la Aljama Almohade pp 229-298, Aula Hernán Ruiz, Cabildo Metropolitano, Granada.

Tabales Rodríguez, M. Á. y Vargas Lorenzo, C. (2014): "La arqueología en el Alcázar de Sevilla: nuevos estudios en el recinto primitivo e investigaciones derivadas de hallazgos casuales (2012-2104)". Apuntes del Real Alcázar de Sevilla, 15, pp. 9-59.

Taylor, R. 2006. Los constructores romanos. Un estudio sobre el proceso arquitectonico, Akal, Madrid.

Thulin, C. 1913. Corpus agrimensorum romanorum, Teubner, Lipsia.

Tubino, F. M. 1999: El Alcázar de Sevilla. Patronato del Real Alcázar. Sevilla.

Vallvé Bermejo, J. 1976: "Notas de metrología hispano-árabe. El codo en la España musulmana". Al-Andalus: revista de las Escuelas de Estudios Árabes de Madrid y Granada, 41, pp. 339-354.

Valor Piechotta, M. 1991: La arquitectura militar y palatina en la Sevilla musulmana. Diputación Provincial de Sevilla. Sevilla.

Valor Piechotta, M. 1993: "La mezquita de Ibn Adabbas de Sevilla: Estado de la cuestión". Estudios de historia y de arqueología medievales 9, pp. 299-314.

Valor Piechotta, M. 2008: Sevilla almohade. Sarriá. Madrid.

Vigil-Escalera, M. 1999: El Jardín Musulmán de la antigua Casa de la Contratación de Sevilla. Consejería de Obras Públicas y Transportes.

Wilson Jones, M. 2003. Principles of Roman Architecture. Yale University Press, New Haven and London.

Wisshak, J.-P. 1989: "Ein Rekonstruktionsmodell der almohadischen Moschee von Tinmal (Marokko)". Madrider Mitteilungen 30, pp. 498-505. 